\title{
Review Article \\ Mechanisms of Drug Resistance in Relapse and Refractory Multiple Myeloma
}

\author{
Wen-Chi Yang ${ }^{1,2,3}$ and Sheng-Fung Lin $^{4,5}$ \\ ${ }^{1}$ Division of Hematology and Medical Oncology, Department of Internal Medicine, Yuan's General Hospital, No. 162, \\ Cheng Kung 1st Road, Kaohsiung 802, Taiwan \\ ${ }^{2}$ Molecular Medicine Lab, Yuan's General Hospital, No. 162, Cheng Kung 1st Road, Kaohsiung 802, Taiwan \\ ${ }^{3}$ Faculty of Meiho University, No. 23, Pingguang Road, Neipu, Pingtung 912, Taiwan \\ ${ }^{4}$ Faculty of Medicine, College of Medicine, Kaohsiung Medical University, No. 100, Tzyou 1st Road, Kaohsiung 807, Taiwan \\ ${ }^{5}$ Division of Hematology and Oncology, Department of Internal Medicine, Kaohsiung Medical University Hospital, No. 100, \\ Tzyou 1st Road, Kaohsiung 807, Taiwan
}

Correspondence should be addressed to Wen-Chi Yang; wenchi890079@gmail.com

Received 21 July 2015; Revised 24 September 2015; Accepted 21 October 2015

Academic Editor: Nicola Amodio

Copyright (c) 2015 W.-C. Yang and S.-F. Lin. This is an open access article distributed under the Creative Commons Attribution License, which permits unrestricted use, distribution, and reproduction in any medium, provided the original work is properly cited.

Multiple myeloma (MM) is a hematological malignancy that remains incurable because most patients eventually relapse or become refractory to current treatments. Although the treatments have improved, the major problem in MM is resistance to therapy. Clonal evolution of MM cells and bone marrow microenvironment changes contribute to drug resistance. Some mechanisms affect both MM cells and microenvironment, including the up- and downregulation of microRNAs and programmed death factor 1(PD-1)/PDL1 interaction. Here, we review the pathogenesis of MM cells and bone marrow microenvironment and highlight possible drug resistance mechanisms. We also review a potential molecular targeting treatment and immunotherapy for patients with refractory or relapse MM.

\section{Introduction}

Multiple myeloma (MM) is a clonal B-cell malignancy that is characterized by the proliferation of a plasma cell clone that produces a monoclonal immunoglobulin. MM leads to endorgan damage diseases such as anemia, hypocalcemia, renal insufficiency, or osteolytic bone lesions [1]. The incidence of MM is around 15,000 per year in the US and Europe, and the median survival is about 4-5 years [2]. In addition to the International and Durie-Salmon staging systems [1], biological markers, including cytogenetic abnormalities such as presence of hypodiploidy, $t(4 ; 14), t(14 ; 16), \operatorname{del}(17 \mathrm{p})$, and del(13), serum $\beta 2$-microglobulin levels greater than $2.5 \mathrm{mg} / \mathrm{L}$, an elevated plasma cell labeling index, and detection of circulating plasma cells, are predictors of poor prognosis in newly diagnosed MM patients [1,3-10]. Over the past decade, new therapeutic strategies for MM have been developed on the basis of a deeper understanding of the biology of myeloma cells and their interaction with the bone marrow (BM) microenvironment. These therapies include novel proteasome inhibitor agents such as bortezomib [11, 12] and immunomodulatory drugs such as thalidomide $[13,14]$ and lenalidomide $[15,16]$. Implementation of these therapies has led to increased longevity in MM patients, with median survival of over 5 years [17]. However, many patients still relapse or become refractory to treatment [18]; therefore, $\mathrm{MM}$ still is an incurable disease, and understanding the disease mechanism is important, specifically for the development of effective treatments.

\section{Myeloma Tumor Cells and the BM Microenvironment}

Plasma cells are derived from hematopoietic cells via Ig VDJ rearrangement, somatic mutation, and Ig class switching [19]. 
Myeloma cells are postgerminal, long-lived plasma cells with mutated homogeneous clonal sequences $[19,20]$. MM cells express CD38 and CD138 antigens on the cell surface but lack CD45 and surface Ig expression [19]. Chromosomal alterations have been detected by conventional karyotyping, interphase fluorescence in situ hybridization (FISH) [21, 22], and spectral karyotyping analysis [23] in 30\%-50\% of MM patients. The results of these analyses have suggested two different pathways of pathogenesis: (1) nonhyperdiploid tumors with a very high incidence of $\mathrm{IgH}$ translocations involving five well-defined recurrent chromosomal translocation areas (11q13 [cyclin D1], 6p21 [cyclin D3], 4p16 [fibroblast growth factor receptor 3, FGFR3], multiple myeloma SET domain [MMSET], 16q23 [c-maf], and 20q11 [mafB]) [24] and relatively high incidence of chromosome 13/13q14 loss and (2) hyperdiploid tumors associated with multiple trisomies involving chromosomes $3,5,7,9,11,15,19$, and 21 , but low incidence of both chromosome 13/13q14 loss and $\operatorname{IgH}$ translocation [25]. These chromosomal alterations lead to dysregulation of cyclin D and selective expansion during interaction with BM stromal cells (BMSCs), which produce interleukin-6 (IL-6) and other cytokines [25].

The BM microenvironment is important for MM pathogenesis. The very-late antigen-4 (VLA-4) on MM cells binds to fibronectin in the serum, and the lymphocyte function associated antigen-1 (LFA-1) on MM cells binds to intercellular adhesion molecule-1 (ICAM1) on BMSCs [26], causing MM cells to home in to the BM. Other cytokines such as tumor-necrosis factor- $\alpha$ (TNF- $\alpha$ ) in the BM can modulate the adhesion of MM cells in the BM by inducing nuclear factor- (NF-) $\kappa \mathrm{B}$. NF- $\kappa \mathrm{B}$-dependent upregulation of cell surface adhesion molecules such as ICAM1 and vascular cell-adhesion molecule-1 (VCAM1), on both MM cells and BMSCs, increases the binding capacity of tumor cells and BMSCs and induces the transcription and secretion of cytokines such as IL-6 and VEGF in BMSCs [27]. Cytokines in the BM microenvironment, such as IL-6, insulin-like growth factor-1 (IGF-1), vascular endothelial growth factor (VEGF), and TNF- $\alpha$, mediate the growth of MM cells. However, IL-6, IGF-1, and IL-21 are associated with tumor cell survival and resistance to apoptosis [28-36]. This association is mediated through the Janus kinase (JAK)/signal transducer and activator of transcription 3 (STAT3) and phosphatidylinositol 3-kinase (PI3K)/AKT pathways. The proliferation of MM cells is triggered by cytokines such as IL-6, IGF-1, VEGF, TNF- $\alpha$, stromal cell derived factor- $1 \alpha$ (SDF- $1 \alpha)$, and IL-21 and is mediated through the RAF/mitogen-activated protein kinase kinase (MEK)/p42/p44/mitogen-activated protein kinase (MAPK) signaling cascade [27, 30, 32, 36-39]. VEGF and SDF- $1 \alpha$ play important roles in cell migration, and the migration of $\mathrm{MM}$ cells is mediated through a protein kinase C- (PKC-) dependent, p42/p44/MAPK-dependent pathway [37, 40, 41].

Immune compromise is a major complication in $\mathrm{MM}$ patients. Programmed death receptor-1 (PD-1, CD279) is a receptor of the Ig superfamily that negatively regulates $\mathrm{T}$ cell antigen receptor signaling by interacting with specific ligands (PD-L1). PD-1 is suggested to play a role in the maintenance of self-tolerance. PD-1 is induced on activated T cells and is expressed on exhausted T cells [42]. Engagement of PD-1 by its ligands, PD-L1 (B7-H1, CD274) or PD-L2 (B7DC, CD273), results in the activation of phosphatases that deactivate signals emanating from the T-cell receptor [43]. Moreover, PD-1 engagement upregulates the expression of basic leucine ATF-like transcription factor (BATF), which in turn impairs T-cell proliferation and cytokine secretion [44]. PD-L1 plays a crucial role in the evasion of the host immune system by tumor cells [45]. PD-L1 is more ubiquitous than PD-L2, and MM cells express elevated levels of PD-L1 [46]. T cells from myeloma-bearing mice and MM patients express higher levels of PD-1. These PD-1-positive T cells were found to be exhausted and produced IL-10 [47, 48]. Stimulation by interferon- $\gamma($ IFN- $\gamma$ ) and Toll-like receptor (TLR) ligands upregulated PD-L1 expression in MM cells from MM patients via the MyD88/TRAF6, MEK, and STAT1 pathway [46].

MicroRNAs (miRNAs) play crucial roles in cancer progression [49], and many miRNAs are deregulated in multiple myeloma. Al Masri et al. reported that the expression levels of $m i R-125 b, m i R-133 a$, $m i R-1$, and $m i R-124 a$ vary in multiple myeloma [50]. Among the 464 miRNAs analyzed, 95 were shown to be expressed at higher levels in patients with MM than in healthy donors [51]; this dysregulation of miRNA expression included upregulation of miR-let-7a, miR-16, $\mathrm{miR}$ 17-5p, miR-19b, miR-21, miR-531, miR-335, miR-342-3p, miR25, $m i R-32, m i R-20 a$, and $m i R-93$; increased expression of the miRNA cluster containing miR-106a, miR-106b, miR181a, miR-19b, miR-181b, miR-92a, and miR-17-92 [52-54]; and downregulation of $m i R-372, m i R-143$, and $m i R-155$ [52]. In patients with monoclonal gammopathy of undetermined significance (MGUS), 41 miRNAs were shown to be upregulated, with $m i R-181, m i R-21, m i R-106 a, m i R-25$, and $m i R-93$ showing the greatest upregulation, whereas seven miRNAs were shown to be downregulated, compared with the levels in healthy plasma cells [55]. These abnormally regulated miRNAs target genes regulating the cell cycle, apoptosis, survival, and cell growth; for example, the miR-17-92 cluster regulates $\mathrm{Bcl}-2$ [56], $m i R-29 b$ regulates MCL1 [57], $m i R-21$ regulates STAT3 in an IL-6-dependent manner [53], and $m i R$ $125 b$ regulates BLIMP1 and IRF4 [58].

\section{Current Biological Based Therapies for MM}

Improved understanding of the pathogenesis and importance of the BM microenvironment in MM has led to the development of two therapeutic categories for MM treatment: proteasome inhibitors and immunomodulatory drugs. These therapies have significantly improved treatment response and survival in MM patients.

3.1. Proteasome Inhibitor. Bortezomib is a proteasome inhibitor that inhibits the activity of the $26 \mathrm{~S}$ proteasome [59]. Bortezomib blocks the degradation of $\mathrm{I} \kappa \mathrm{B} \alpha$, an inhibitory protein that is constitutively bound to cytosolic NF- $\kappa \mathrm{B}$, thereby inhibiting the nuclear translocation and activation of NF- $\kappa$ B. Bortezomib induces apoptosis by activating caspase- 8 and caspase- 9 in drug-resistant MM cell lines and primary cancer cells derived from MM patients. Moreover, 
bortezomib downregulates the expression of adhesion molecules on MM cells and BMSCs and their related binding. Bortezomib also inhibits IL-6 and/or BMSC/MM cell adherence-induced p42/p44 MAPK phosphorylation and proliferation of MM cells [60, 61].

Bortezomib has received full FDA approval for the treatment of relapse, refractory, and newly diagnosed MM patients based on the results of phase III trials [11, 12]. Treatment regimens including bortezomib have become the standard treatment for multiple myeloma patients, particularly for hematopoietic stem cell transplantation-eligible patients, because of the improved response rate and survival compared to chemotherapy and steroid treatment alone [11, 62-75].

3.2. Thalidomide and IMiDs. Thalidomide and the more potent second-generation thalidomide analogues, IMiDs, target myeloma cells in the BM microenvironment. They inhibit TNF- $\alpha$ production $[75,76]$ and angiogenesis by blocking the angiogenic growth factors, basic fibroblast growth factor (bFGF), and VEGF [77]. Specifically, these agents trigger caspase-8-mediated apoptosis and enhance both caspase-8mediated MM cell apoptosis, triggered by FAS or TRAIL, and caspase-9-mediated MM cell killing, triggered by dexamethasone [78-80]. They also block the induction of cytokines such as IGF-1 and IL- 6 and VEGF secretion triggered by MM cell adherence to BMSCs. In addition, they inhibit angiogenesis and augment natural killer cell activity against autologous MM cells [79-82]. Several clinical trials have demonstrated the benefits of using regimens involving thalidomide or IMiDs (lenalidomide) for MM treatment, particularly in combination with proteasome inhibitors $[15,16,63-66,69-$ 71, 74, 83-96]. This combined therapy has become the standard regimen for MM treatment. Pomalidomide therapy has afforded prolonged progression-free survival in patients who relapsed or became refractory to lenalidomide treatment [97].

The choice of therapy for patients is influenced by a variety of factors, including age, comorbidities, and eligibility for stem cell transplantation. Treatment strategies for MM patients include two-drug regimens such as bortezomibdexamethasone [62], lenalidomide-dexamethasone $[15,16$, $86,94]$, or thalidomide-dexamethasone $[63,84,92,93]$ and three-drug regimens such as bortezomib-thalidomidedexamethasone [63-66], bortezomib-melphalan-prednisone $[68,69]$, or lenalidomide-bortezomib-dexamethasone (RVD) [98]. However, RVD has shown the most promising effect.

\section{Mechanisms of Drug Resistance}

During conventional chemotherapy such as treatment with vincristine and doxorubicin, accumulation of drugs induces the expression of multidrug resistance (MDR) genes and p-glycoprotein in tumor cells [99-101]. The BM microenvironment can confer drug resistance through two major mechanisms (Figure 1(a)) [102]: (1) tumor cell adhesion, which involves MM cell binding to fibronectin, which in turn induces KIP1 and G1 growth arrest and confers cell-adhesion mediated drug resistance $[103,104]$ and (2) cytokinemediated antiapoptotic sequelae, which involve the induction of JAK/STAT and PI3K/AKT signaling by cytokines in the $\mathrm{BM}$ microenvironment, which in turn mediates resistance to conventional and novel therapies. IL-6 induces resistance to dexamethasone by activating JAK/STAT signaling and upregulating the antiapoptotic proteins, BCL-XL $[105,106]$ and myeloid cell leukemia sequence-1 (MCL1) [107, 108]. IL-6 also activates SRC-homology tyrosine phosphatase 2 (SHP2), which blocks dexamethasone-induced activation of RAFTK and apoptosis [109]. Both IL-6 and IGF-1 inhibit drug-induced apoptosis of MM cells through PI3K/AKT signaling and NF- $\kappa \mathrm{B}$ activation, which in turn induces the intracellular expression of downstream inhibitor of apoptosis proteins (IAPs), FLICE-inhibitory protein (FLIP), survival, cellular inhibitor of apoptosis-2 (cIAP2), A1/BFL1, and Xlinked inhibitor of apoptosis protein (XIAP) [32, 35, 110, 111]. Neither bortezomib nor thalidomide/IMiDs can block JAK/STAT or PI3K/AKT signaling [102].

MicroRNAs play a key role in multidrug resistance in cancers by modulating drug transporter-related proteins, cell cycle-related proteins, drug targets, autophagy, the tumor microenvironment, cell survival signaling, and apoptosis pathways $[112,113]$. Roccaro et al. reported that the expression of $m i R-15 a$ and $m i R-16$ decreased, while the expression of $m i R-221, m i R-222, m i R-382, m i R-181 a$, and $m i R-181 b$ increased in patients with relapse/refractory MM compared with the levels in healthy volunteers [114]. Moreover, $m i R-15 a$ and $m i R-16$ regulate the cell cycle by inhibiting the expression of cyclin D1, cyclin D2, and CDC25A and the phosphorylation of $\mathrm{Rb}$, resulting in $\mathrm{G}_{1}$ arrest. $m i R-15 a$ and $m i R-16$ can also reduce the expression of $\mathrm{Bcl}-2$. Cells transfected with premiRNA-15a and pre-miRNA-16-1 exhibit the following effects: (1) increased phosphorylation of the inhibitory protein $I \kappa B$ in the cytoplasm, indicating involvement of these miRNAs in both the canonical and noncanonical NF- $\kappa \mathrm{B}$ pathways; (2) significantly decreased VEGF secretion, suggesting an antiangiogenic role for these miRNAs; (3) and inhibition of migration in response to SDF-1. Significant inhibition of the adhesion of MM to primary BM stromal cells upon application of these miRNAs has been confirmed in mouse models. In addition, the $m i R-15 a / m i R-16-1$ cluster upregulates several genes, including NEDD9, Snai2, MALAT1, and VEGF, and leads to the inhibition of tumor progression by enhancing tumor cell survival, metastasis, and the angiogenic properties of MM cells [115]. Neri et al. reported the dysregulation of several miRNAs related to bortezomib resistance, including the overexpression of $m i R-155, m i R-342-3 p, m i R-181 a, m i R-$ $181 b, m i R-128$, and $m i R-20 b$ and the downregulation of $m i R-$ let-7b, miR-let-7i, miR-let-7d, miR-let-7c, miR-222, miR-221, $m i R-23 a, m i R-27 a$, and $m i R-29 a$ [116]. The predicted targets genes include genes involved in cell cycle regulation, cell growth, apoptosis, and the ubiquitin-conjugation pathways [115]. miR-21 targets Rho-B, PTEN, and BTG2 and controls STAT-3/IL-6-dependent pathways as well as AKT and NF$\kappa \mathrm{B}$ signaling via myeloma cell adhesion to BMSCs [117-119]. $m i R-21$ inhibitor exhibits synergistic effects with dexamethasone, doxorubicin, and bortezomib [117], indicating that $m i R$ 21 may be involved in mediating drug resistance. Another 


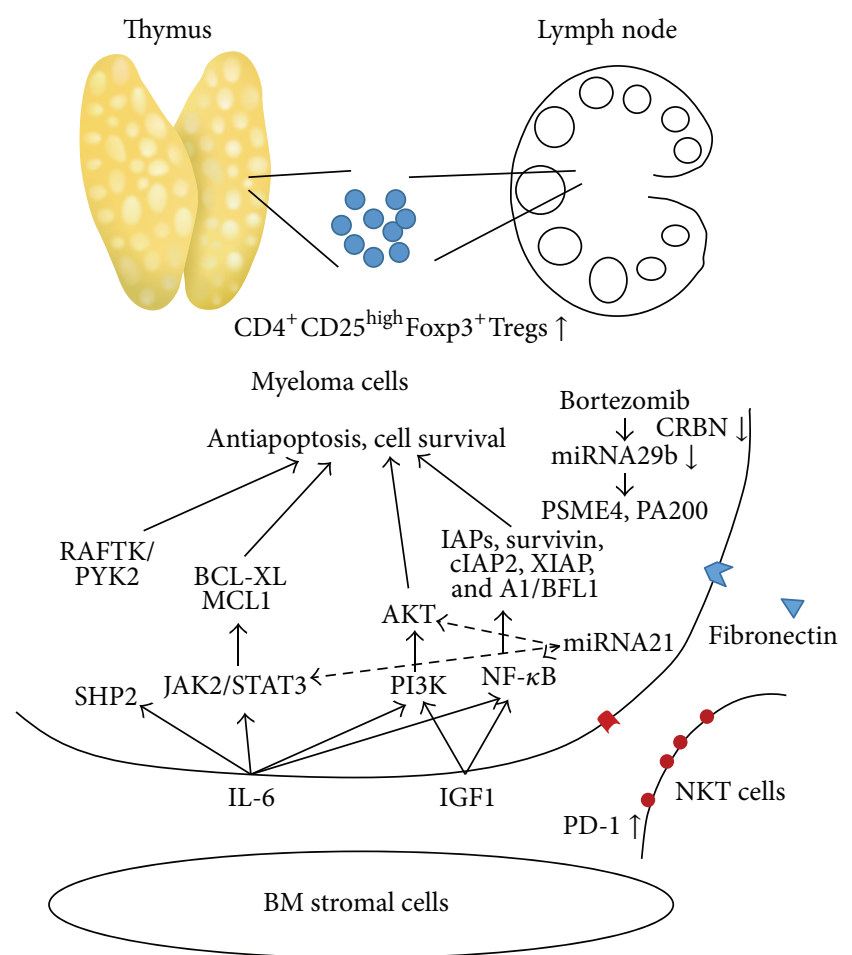

(a)

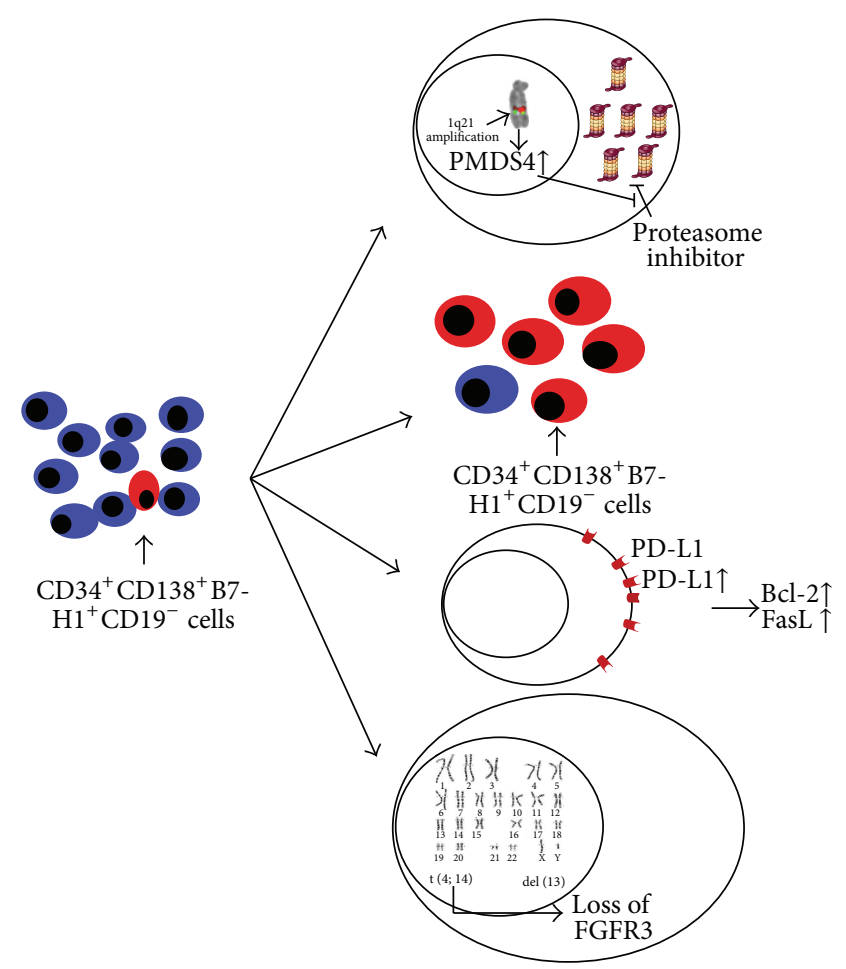

(b)
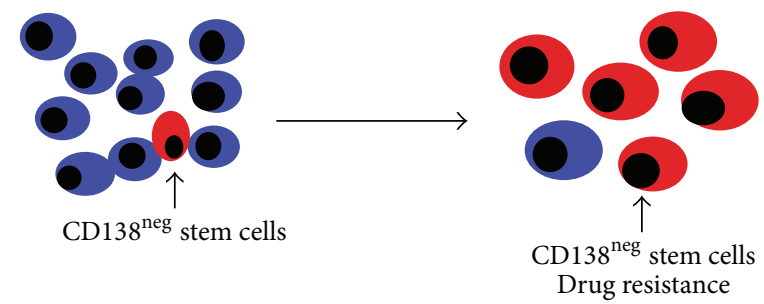

(c)

Figure 1: The mechanism of drug resistance of refractory and relapse multiple myeloma. (a) Microenvironment, (b) clonal evolution of myeloma cells, and (c) cancer stem cell.

miRNA, $m i R-29 b$, has been shown to target PSME4, which encodes the proteasome activator PA200; this miRNA is significantly downregulated in bortezomib-resistant cells and in cells resistant to second-generation proteasome inhibitors, for example, carfilzomib and ixazomib [120]. Bortezomib promotes the accumulation of polyubiquitinated proteins and induces aggresome and autophagosome formation to promote protein clearance, tumor survival, and relative drug resistance. Activating transcription factor 4 (ATF4), an endoplasmic reticulum-resident transmembrane protein, and microtubule-associated protein 1 light chain 3B (LC3B), one of the key factors in autophagosome formation, play a critical role in activating autophagy and protecting breast cancer cells from bortezomib-induced cell death, representing another potential mechanism of resistance to bortezomib [121].

Clonal evolution of MM cells is another possible mechanism of drug resistance (Figure 1(b)). Hyperexpression of the proteasome-related gene, PSMD4, is highly sensitive to chromosome 1q21 amplification and is reported to be associated with bortezomib resistance [122]. MM with gain of chromosome 1q has demonstrated poor prognosis [123], and patients with relapse or refractory MM who received treatment with lenalidomide and dexamethasone in the presence of $\operatorname{del}(13)$ and $t(4 ; 14)$ chromosomal abnormalities exhibited lower response rates and shorter median progression-free survival (PFS) [4]. Chromosome $t(4 ; 14)$ is likely to evolve over time, first to a chimeric and ultimately to an unbalanced translocation, with the associated loss of FGFR3 expression, which indicates disease progression [124]. B7-H1 (PD-L1) expression is upregulated on the surface of cells from MM patients. Compared to $\mathrm{B} 7-\mathrm{H1}^{-}$human myeloma cell lines (HMCLs), B7- $\mathrm{H1}^{+} \mathrm{HMCL}$ were found to be more proliferative and less susceptible to dexamethasone and melphalan treatment and were accompanied by higher Bcl-2 and FasL expression [125, 126]. The expression levels of PD-L1 were found to be upregulated after myeloma patients relapsed or became refractory to therapy [126]. Kuranda 
et al. also reported that a small subpopulation of cycling $\mathrm{CD} 34^{+} \mathrm{CD} 138^{+} \mathrm{B} 7-\mathrm{H}^{+} \mathrm{CD} 19^{-}$plasma cells were found in $\mathrm{MM}$ patients, and these cells often expressed Ki67, a marker for proliferation, and limited the clinical benefits of autologous CD $34^{+}$cell transplantation [127]. However, a population of suppressive $\mathrm{CD} 4^{+} \mathrm{CD} 25^{\text {high }} \mathrm{Foxp}^{+}$regulatory T cells (Tregs) accumulated in the thymus and lymphoid peripheral organs during disease progression [128].

Another mechanism of drug resistance involves epigenetic inactivation of genes such as RASD1. Methylation of $R A S D 1$, which encodes a Ras family protein that is induced by dexamethasone and suppresses cell growth, was found to be associated with its inactivation, which correlated with resistance to dexamethasone [129].

The concept of cancer stem cells was introduced in the late 1990s. Traditionally, cancer cells that survive chemotherapy and acquire drug resistance are thought to give rise to a population of drug-resistant cancer cells through modulation of mechanisms such as drug inactivation, changes in the expression of cellular targets, suppression of drug accumulation, and inhibition of drug activation [130-132]. The Notch, Wnt, and Hedgehog pathways play a role in regulating normal stem cells and the pathogenesis of a wide variety of human cancers, including MM [133-137]. Aberrant activation of Hedgehog signaling has been identified in MM. Pathway activation by ligands results in the expansion of immature myeloma cells, whereas the inhibition of signaling with a ligand-neutralizing monoclonal antibody or antagonists of the positive mediator of the pathway signaling induces plasma cell differentiation [137, 138]. Matsui et al. identified a group of $\mathrm{CD} 138^{\text {neg }} \mathrm{MM}$ cells that possess high drug efflux capacity and intracellular drug detoxification activity. Alternatively, MM cells expressing the memory B-cell markers CD20 and CD27 from the peripheral blood could give rise to clonogenic MM growth in vitro and in SCID/NOD mice [139]. These data support the hypothesis that MM cells exhibit stem cell characteristics.

Cereblon (CRBN) is the primary target of thalidomide teratogenicity [140]. Thalidomide binds to CRBN, alters the function of the E3 ubiquitin ligase complex, and induces downstream effects, including cell cycle arrest caused by the upregulation of the cyclin-dependent kinase inhibitor p $21^{\text {WAF-15 }}$ and the downregulation of interferon regulatory factor 4 (IRF4), which targets critical genes, including $M Y C$, CDK6, and CASP [141-143]. CRBN is also required for the anti-MM action of the thalidomide derivatives lenalidomide and pomalidomide; decreasing the expression of CRBN results in resistance to IMiDs, as evidenced by both in vitro and clinical studies [144-148]. However, the majority of patients with low CRBN levels do not harbor genomic mutations [149].

\section{Potential New Therapies for Refractory and Relapse MM Patients}

5.1. Second-Generation Inhibitors of the Ubiquitin-Proteasome Cascade [150]. Recently, potent inhibitors with chymotryptic activity have been developed. These include carfilzomib,
ONX 0912, and MLN 9708 [151, 152], which can overcome bortezomib resistance, as demonstrated in preclinical and early clinical trials. Carfilzomib was approved by the FDA in July 2012 to treat relapse and refractory MM patients who had received prior treatment with bortezomib and thalidomide/lenalidomide [153, 154]. The safety and efficacy of carfilzomib were demonstrated in the PX-171-003-A1 trial, a prospective phase II trial in patients with relapse or refractory MM who had received at least two prior therapies, including a proteasome inhibitor and an immunomodulatory agent [155]. A randomized phase III clinical trial comparing carfilzomib-lenalidomidedexamethasone and lenalidomide-dexamethasone treatment regimens in patients with relapse MM [156] and another randomized phase III clinical trial comparing carfilzomibdexamethasone and bortezomib-dexamethasone in patients with relapse MM [157] are ongoing. ONX 0912 [151] and MLN 9708 [158] are novel orally bioavailable proteasome inhibitors that trigger apoptosis by activating caspase- 3 , caspase- 8 , and caspase-9. Ongoing phase I and II clinical trials for these inhibitors have shown promising results [159-161].

P5091 is another second-generation proteasome inhibitor that targets the deubiquitinating enzyme USP7 and induces apoptosis in MM cells resistant to conventional and bortezomib therapies [162]. NPI-0052 is a broader proteasome inhibitor that targets chymotryptic, tryptic, and caspase-like activities to overcome bortezomib resistance in preclinical studies [163]. PR-924, an inhibitor of the LMP-7 immunoproteasome subunit, also blocks MM cell growth in vitro and in vivo [164].

5.2. Immunomodulatory Agents [150]. Pomalidomide is a distinct oral IMiD immunomodulatory agent with direct antimyeloma, stromal-support inhibitory, and immunomodulatory effects. Pomalidomide can synergize in vitro with proteasome inhibitors such as bortezomib [79]. Phase 1 clinical studies of pomalidomide in combination with lowdose dexamethasone have demonstrated the effectiveness of this therapy in MM patients who were resistant to other agents, including thalidomide, lenalidomide, and bortezomib $[165,166]$. The pivotal multicenter, open-label, randomized phase III trial, MM-003, compared pomalidomide and lowdose dexamethasone with high-dose dexamethasone in 455 patients with refractory or relapse MM after failure of bortezomib and lenalidomide treatment. Pomalidomide and lowdose dexamethasone induced better progression-free survival and favorable overall survival without cross-resistance of prior treatment of lenalidomide and/or thalidomide [167].

5.3. PD-1/PD-L1 in Multiple Myeloma [150]. PD-L1 expression is increased in MM cells, and PD-1 is expressed on a relatively large number of $\mathrm{T}$ cells in myeloma-bearing mice, but only in sites of tumor accumulation [48]. Binding of PD-L1 to PD-1 expressed on the surface of activated T cells delivers an inhibitory signal, thereby reducing cytokine production and proliferation [168]. Preclinical data have confirmed the important role of the PD-1 pathway in immune evasion by $\mathrm{MM}$ cells $[46,48,168]$. In phase I clinical trials, objective responses were observed in patients with 
melanoma, renal cell carcinoma, and non-small cell lung cancer, who underwent immunotherapy with an anti-PD-1 monoclonal antibody [169-172]. In addition, an anti-PD-L1 monoclonal antibody exhibited antitumor activity in patients with melanoma, renal cell carcinoma, non-small cell lung cancer, and ovarian cancer $[172,173]$. Pidilizumab (CT011), an anti-PD1 antibody, enhances NK-cell activity against autologous, primary MM cells. In addition, lenalidomide downregulates PD-L1 in MM cells and may augment CT011-mediated enhancement of NK-cell activity against MM [47]. However, another anti-PD1 antibody, nivolumab (BMS936558), did not show objective responses in MM [174]. This may be attributed to the fact that the mechanism of action of T-cell activity against MM cells does not involve PD-1/PD-L1 interaction. Clonal cytotoxic $\mathrm{CD}^{+} \mathrm{T}$ cells are the only definitive $\mathrm{T}$ cells that have a protective role and impact on survival in MM [175]. Cytotoxic T-cell clones $\left(\mathrm{CD} 57^{+} \mathrm{CD} 28^{-} \mathrm{TCRV} \beta\right.$ restricted) were found to be present in $51 \%$ of 264 patients with MM. These protective T cells exhibit telomere-independent senescence, rather than the exhausted or anergic phenotype [176]. Suen et al. demonstrated that PD1 expression is downregulated in clonal BM cytotoxic T cells, compared with the levels in nonclonal T cells, in MM patients [177]. Thus, the role of PD-1 or PD-L1 blockade needs to be investigated in detail, and clinical trials need to be performed to evaluate its therapeutic potential.

5.4. Antibody-Related Therapies. Several antigens that exhibit strong expression in MM cells, including CD38, CD138, CD56, CD74, CD40, insulin-like growth factor1 receptor (IGF-1R), signaling lymphocyte activatingmolecule F7 (SLAMF7), and immunoglobulin superfamily member FcRL5, may be candidates for antibody-related immunotherapy [178]. Numerous naked antibodies have been tested in preclinical myeloma models, and antibodies against six antigens, that is, CD38, CD74, CD40, SLAMF7, IL-6, and IGF-1R, have been examined in clinical trials. Daratumumab [179] and SAR650984 [180] are anti-CD38 monoclonal antibodies that have shown satisfactory response rates in patients with relapse/refractory $\mathrm{MM}$ and $\mathrm{CD} 38^{+}$ hematological malignancies (including 27 patients with $\mathrm{MM}$ ) in separate phase I clinical trials. A phase II study of daratumumab plus proteasome inhibitor in patients with IMiD refractory myeloma and a phase I/II study of the combination of lenalidomide and dexamethasone are currently underway $[181,182]$. SAR650984 is currently being tested in a phase I dose-escalation study and a phase Ib combination study with lenalidomide and dexamethasone [183, 184]. Milatuzumab [185], an anti-CD74 monoclonal antibody, resulted in only $26 \%$ of patients achieving stable disease (SD), with a $0 \%$ overall response rate (ORR) in patients with refractory/relapse MM. Dacetuzumab [186] and lucatumumab [187] are anti-CD40 monoclonal antibodies that yielded ORRs of $0 \% \quad(20 \%$ of patients achieving SD) and $4 \%$ ( $43 \%$ of patients achieving SD), respectively. However, there are no trials currently underway in patients with MM. Elotuzumab, an anti-SLAMF7 (CS1) monoclonal antibody, yielded no objective responses in a phase I clinical trial [188]. However, the combination of elotuzumab, lenalidomide, and dexamethasone yielded an ORR of $84 \%$ in patients with refractory/relapse MM in a phase II clinical trial [189]. In a recent phase III study, 321 patients with relapse/refractory MM received elotuzumab plus lenalidomide and dexamethasone, and 325 patients with relapse/refractory MM received the control treatment of lenalidomide and dexamethasone. After a median followup of 24.5 months, the rates of progression-free survival (PFS) at 1 and 2 years were $68 \%$ and $41 \%$, respectively, in the elotuzumab group as compared with $57 \%$ and $27 \%$, respectively, in the control group. Median PFSs were 19.4 and 14.9 months in the elotuzumab and control groups, respectively, and the ORRs were $79 \%$ and $66 \%$ in the elotuzumab and control groups, respectively [190]. The antiIGF-1R antibody figitumumab (CP-751871) and AVE 1642 showed disappointing results in phase I studies [191, 192]. However, treatment with the IGF-1R inhibitor OSI-906 or transfection with IGF-1R-targeting small hairpin RNA had synergistic effects on bortezomib sensitivity in cell lines and patient samples [193]. Siltuximab, another monoclonal antibody targeting IL-6, had minimal effects in a phase I study $[194,195]$ and exhibited no benefits in a phase II clinical trial in patients with refractory/relapse MM [196].

Another type of antibody-related therapy is antibodydrug-conjugated therapy. The anti-CD138 antibody-drug conjugate (ADC), indatuximab ravtansine (BT062), had an ORR of $11 \%$, with $41 \%$ achieving SD, in 27 patients with relapse/refractory MM in a phase I study [197]. Combined with lenalidomide and dexamethasone, this ADC resulted in an ORR of $78 \%$ in nine patients [198]. The anti-CD56 ADC lorvotuzumab, mertansine, yielded an ORR of $17 \%$, with $28 \%$ achieving SD, in selected patients with MM exhibiting CD56 expression in a phase I study [199]. A few additional ADCs are currently being examined in preclinical studies, including ADCs targeting CD74, Fc receptor-like 5 (FcRL5), and B-cell maturation antigen (BCMA). Milatuzumab, an anti-CD74 antibody conjugated to doxorubicin, shows in vitro and in vivo activity against MC/CAR cells and MC/CAR xenografts in SCID mice [200]. The anti-FcRL5 maytansine analog (DM4) and monomethyl auristatin E (MMAE) have activities similar to those of bortezomib (biweekly treatment) in the inhibition of tumor growth in subcutaneous xenografts of OPM2-FcRL5 and EJM-FcRL5 cells in SCID mice and have been shown to be well tolerated in monkeys in a preclinical study [201]. An anti-BCMA antibody conjugated to monomethyl auristatin F (MMAF) has been reported to show rapid internalization, efficient trafficking to lysosomes, and high antigen recycling rates by $6 \mathrm{~h}$ after administration [202]. The anti-BCMA ADC GSK2857916 also resulted in elimination of xenografts arising from myeloma cells [203].

Chimeric antigen receptor- (CAR-) modified T-cell therapy is a new type of immunotherapy. Adoptive transfer of $\mathrm{T}$ cells engineered to express chimeric antigen receptors (CARs) can specifically recognize tumor-associated antigens, combining the advantages of non-major histocompatibility complex- (MHC-) restricted recognition with efficient $\mathrm{T}$ cell activation and expansion [204-207]. CARs combine the antigen recognition domain of the antibody with the intracellular domain of the T-cell receptor- $\zeta(\mathrm{TCR}-\zeta)$ chain 
or $\mathrm{F} c \gamma \mathrm{RI}$ protein into a single chimeric protein that is capable of triggering $\mathrm{T}$-cell activation in a manner very similar to that of the endogenous TCR [208, 209]. CS-1 is a cell surface glycoprotein of the signaling lymphocyte activation molecule (SLAM) receptor family that is highly and selectively expressed on normal plasma cells and MM cells, with lower expression on NK cells and little or no expression on normal tissues. CS1-CAR NK cells exhibit enhanced MM cytolysis and IFN- $\gamma$ production and exhibit tumor suppressive effects on MM cell lines, primary MM tumor cells, and MM xenograft mouse models [210, 211]. CD138 is highly expressed on MM cells and is involved in the development and/or proliferation of these cells [212]. Guo et al. reported that four out of five patients with chemotherapyrefractory MM treated with CART-138 therapy achieved SD longer than 3 months [213]. In a preclinical study, antiBCMA-CAR-transduced $\mathrm{T}$ cells exhibited BCMA-specific functions, including cytokine production, proliferation, cytotoxicity, and in vivo tumor eradication. Importantly, antiBCMA-CAR-transduced $\mathrm{T}$ cells recognize and kill primary MM cells [214]. A clinical trial examining CART-19 combined with autologous stem cell transplantation (ASCT) in patients with early refractory/relapse $\mathrm{MM}$ is currently underway [215].

5.5. Histone Deacetylase Inhibitors [150]. Deacetylases are a group of enzymes that affect various intracellular proteins, including histones, transcription factors, and molecular chaperones, which modulate gene expression, cellular differentiation, and survival [102]. Deacetylase inhibitors (DACi), including panobinostat and vorinostat, have been evaluated for the treatment of MM. The addition of proteasome inhibitors to DACi treatment regimens enhances the sensitivity of MM cells to DACi to induce mitochondrial dysfunction, caspase- 9 , caspase- 8 , and caspase- 3 activation, and poly (ADP-ribose) polymerase degradation, which is associated with NF- $\kappa \mathrm{B}$ inactivation, c-Jun $\mathrm{NH}_{2}$-terminal kinase activation, p53 induction, caspase dependent cleavage of $\mathrm{p} 21^{\mathrm{CIP} 1}, \mathrm{p} 27^{\mathrm{KIP} 1}$, and Bcl-2, and cyclin D1 downregulation [216]. The mechanism of this synergistic apoptotic effect on MM cells is multifactorial and includes disruption of protein degradation and inhibition of the interaction of MM cells with the tumor microenvironment [217]. Rocilinostat (ACY1215) is HDAC6 inhibitor that targets aggressomal protein degradation systems. A synergistic antitumor effect of ACY1215 and proteasome inhibitors was observed in MM. In addition, a potential benefit was observed in MM-related bone diseases with the combination of these two drugs [218, 219].

5.6. Other Agents. Other drugs, including cell signaling targeted therapies (PI3K/AKT/mTOR, p38 MAPK, Hsp90, Wnt, Notch, Hedgehog, and cell cycle) and strategies targeting the tumor microenvironment (hypoxia, angiogenesis, integrins, CD44, CXCR4, and selectins) are candidates for the treatment of refractory and relapse MM [220]. PI3K/AKT is upregulated during refractory and relapse MM. Bortezomib and IMiDs (thalidomide and lenalidomide) do not impact PI3K/AKT signaling [102]. The PI3K/AKT pathway regulates apoptosis, cell cycle, and tumor proliferation [221]. AKT indirectly activates mTOR, a complicated checkpoint of cellular growth influenced by growth factor signaling, adenosine monophosphate levels, and nutrient and $\mathrm{O}_{2}$ availability [222]. Perifosine (KRX-0401) is an oral bioactive alkylphospholipid that is thought to target cell membranes and modulate multiple signaling pathways, including the inhibition of AKT and promotion of apoptosis in MM cells [223]. A phase I study with perifosine in combination with lenalidomide and dexamethasone [224] and a phase I/II study with perifosine in combination with bortezomib with or without dexamethasone in refractory and relapse MM [225] demonstrated high treatment tolerance and beneficial effects on survival. Rapamycin and some analogues (temsirolimus or CCI-779 and everolimus or RAD001) are inhibitors of mTOR and have shown preclinical potential as MM therapies. Phase I/II clinical trials using temsirolimus and everolimus in heavily pretreated MM patients showed high tolerance and acceptable response rates [226, 227]. NVP-BEZ235 is a dual pan inhibitor of the PI3K/AKT/mTOR pathways at the levels of PI3K and mTOR, which inhibits growth and proliferation in MM. Moreover, synergism studies have revealed synergistic and additive effects of NVP-BEZ235 in combination with melphalan, doxorubicin, and bortezomib [228]. P38 is constitutively activated in human myeloma and has been implicated in osteoclast and osteoblast activity and bone destruction [229]. The effect of a p38 alpha-selective MAPK inhibitor, SCIO-469 (indole-5-carboxamide, ATPcompetitive inhibitor), or its structural analogue, SD-282 (indole-5-carboxamide, ATP-competitive inhibitor), reduced human myeloma cell growth in vivo at early and advanced phases of the disease; the same study also provided evidence of the potential for cotherapy with dexamethasone in mouse models of MM [230]. However, LY2228820, a p38 MAPK inhibitor, significantly enhanced toxicity in MM patients [231]. Therefore, more studies on this pathway are required for the development of safe and effective compounds.

Tanespimycin, an Hsp90 inhibitor, reduces tumor cell survival in vitro by affecting the IL- 6 receptor and elements of the PI3K/AKT and MAPK signaling pathways, through abrogation of the protective effect of BMSCs. Tanespimycin is known to inhibit angiogenesis [232]. A phase I/II study with tanespimycin and bortezomib in relapse/refractory MM patients showed acceptable toxicity and durable response rates [233].

Cancer stem cells use many of the same signaling pathways that are found in normal stem cells, such as Wnt, Notch, and Hedgehog ( $\mathrm{Hh})$. Agents targeting these pathways would complement current treatment approaches [234-237]. Other agents targeting the cell cycle, such as seliciclib [238] and LCQ195 [239], cyclin D kinase (CDK) inhibitors, and MLN8237 [240], an aurora-A kinase inhibitor, have demonstrated therapeutic benefits in MM in a preclinical setting.

TNF-related apoptosis-inducing ligand or Apo ligand (TRAIL/Apo2L) is a member of a superfamily of cell deathinducing ligands which also includes TNF- $\alpha$ and Fas ligand (FasL or CD95L) [241]. In a preclinical study, TRAIL/Apo2L selectively induced apoptosis in human MM cells, including cells that were sensitive or resistant to dexamethasone 
and doxorubicin [78], and reversed the bortezomib-induced upregulation of $\beta$-catenin, MCL1, and FLIP, thereby enhancing the cytotoxicity of combination therapy [242]. This treatment may represent a promising candidate for targeted therapy.

In $\mathrm{MM}$, the impacts of tumor microenvironmental factors such as hypoxia, angiogenesis, and interactions between MM and BMSCs have become an important consideration for understanding disease progression and resistance to therapy and have been incorporated into novel drug screening approaches. VEGFR antagonists inhibit angiogenesis in the MM microenvironment [243]. However, the clinical data for VEGFR antagonists, including pazopanib [244], vandetanib [245], and SU5416 [246], have demonstrated disappointing results.

SDF-1 is produced by BM-derived stromal cells, and its receptor CXCR4 is expressed on the surface of normal and MM cells. The SDF-1/CXCR4 axis is a key regulator of MM cell homing, adhesion, and motility [247]. The CXCR4 antagonist AMD3100 was shown to block MM cell interactions with the BM microenvironment and consequent signaling responses, leading to enhanced sensitivity to therapy [248]. In a phase I trial of plerixafor and bortezomib as a chemosensitization strategy in relapse or relapse/refractory MM patients, preliminary results showed that the combination is well tolerated and demonstrates an acceptable response rate [249].

Mitochondria are important organelles involved in apoptosis under conditions of oxidative stress. Chauhan et al. reported that combining PK-11195, an antagonist of the mitochondrial peripheral benzodiazepine receptors (PBRs), with bortezomib triggers synergistic anti-MM activity, even in MM cells resistant to doxorubicin, melphalan, thalidomide, dexamethasone, and bortezomib. The mechanism through which apoptosis is induced includes loss of mitochondrial membrane potential, superoxide generation, release of the mitochondrial proteins cytochrome-c and Smac, activation of caspase-8/caspase-9/caspase-3, and activation of c-Jun $\mathrm{NH}_{2}$ terminal kinase (JNK) [250].

\section{Conclusion}

Based on a thorough understanding of the mechanism and importance of the MM microenvironment, proteasome inhibitors, such as bortezomib, have been developed in combination with IMiDs and steroids to provide dramatic improvement in treatment response and survival in MM patients. However, MM is still an incurable disease. The possible mechanisms of drug resistance include MDR gene polymorphism and p-glycoprotein overexpression in MM cells, microenvironmental changes (cell adhesion, activation of cytokine-related antiapoptosis pathways such as the JAK/STAT and PI3K/AKT pathways), clonal evolution such as hyperexpression of the proteasome-related gene, PSMD4, related to chromosome $1 \mathrm{q} 21$ amplification, $\mathrm{t}(4 ; 14)$ unbalanced translocation, and selected $\mathrm{CD} 34^{+} \mathrm{CD} 138^{+} \mathrm{B} 7-$ $\mathrm{H}^{+} \mathrm{CD} 19^{-}$plasma cell accumulation after treatment. The up- and downregulation of various miRNAs modulate MM cell survival, cell cycle, and microenvironment, thereby contributing to drug resistance, including against bortezomib.
PD-1 is enriched on T cells in MM patients, and PD-L1 expression on MM cells is enhanced. PD-1/PD-L1 interactions have been shown to mediate tumor escape from immune control in a number of animal models. Moreover, $\mathrm{PD}-1 / \mathrm{PD}-\mathrm{L1}$ interactions are related to immune dysfunction in $\mathrm{MM}$ patients. PD-L1 in MM cells and PD-1 in T cells surrounding tumors contribute to drug resistance mechanisms. Potential therapies, including second-generation proteasome inhibitors, new immunomodulatory agents, DACi, and kinase inhibitors such as the mTOR inhibitor, as well as drugs targeting cytokine-related pathways, anti-PD-1/antiPD-L1 monoclonal antibodies, and monoclonal antibodies (naked or conjugated with drugs), and CAR-T therapy, are under preclinical and clinical investigation to provide better treatment responses in MM patients. Study of the pathophysiology of MM and the mechanisms of drug resistance will enable the development of novel therapeutic strategies to cure this disease. Further clinical trials of the novel agents described here are also necessary, especially for refractory/relapse MM patients.

\section{Conflict of Interests}

The authors declare that there no financial or nonfinancial competing interests.

\section{References}

[1] R. A. Kyle and S. V. Rajkumar, "Criteria for diagnosis, staging, risk stratification and response assessment of multiple myeloma," Leukemia, vol. 23, no. 1, pp. 3-9, 2009.

[2] N. Korde, S. Y. Kristinsson, and O. Landgren, "Monoclonal gammopathy of undetermined significance (MGUS) and smoldering multiple myeloma (SMM): novel biological insights and development of early treatment strategies," Blood, vol. 117, no. 21, pp. 5573-5581, 2011.

[3] H. Avet-Loiseau, M. Attal, P. Moreau et al., "Genetic abnormalities and survival in multiple myeloma: the experience of the Intergroupe Francophone du Myélome," Blood, vol. 109, no. 8, pp. 3489-3495, 2007.

[4] H. Avet-Loiseau, J. Soulier, J.-P. Fermand et al., "Impact of highrisk cytogenetics and prior therapy on outcomes in patients with advanced relapsed or refractory multiple myeloma treated with lenalidomide plus dexaméthasone," Leukemia, vol. 24, no. 3, pp. 623-628, 2010.

[5] N. V. Smadja, C. Bastard, C. Brigaudeau, D. Leroux, and C. Fruchart, "Hypodiploidy is a major prognostic factor in multiple myeloma," Blood, vol. 98, no. 7, pp. 2229-2238, 2001.

[6] R. Fonseca, B. Barlogie, R. Bataille et al., "Genetics and cytogenetics of multiple myeloma: a workshop report," Cancer Research, vol. 64, no. 4, pp. 1546-1558, 2004.

[7] R. Fonseca, E. Blood, M. Rue et al., "Clinical and biologic implications of recurrent genomic aberrations in myeloma," Blood, vol. 101, no. 11, pp. 4569-4575, 2003.

[8] T. Facon, H. Avet-Loiseau, G. Guillerm et al., "Chromosome 13 abnormalities identified by FISH analysis and serum $\beta 2$ microglobulin produce a powerful myeloma staging system for patients receiving high-dose therapy," Blood, vol. 97, no. 6, pp. 1566-1571, 2001. 
[9] P. R. Greipp, J. A. Lust, W. M. O’Fallon, J. A. Katzmann, T. E. Witzig, and R. A. Kyle, "Plasma cell labeling index and beta 2-microglobulin predict survival independent of thymidine kinase and C-reactive protein in multiple myeloma," Blood, vol. 81, no. 12, pp. 3382-3387, 1993.

[10] G. S. Nowakowski, T. E. Witzig, D. Dingli et al., "Circulating plasma cells detected by flow cytometry as a predictor of survival in 302 patients with newly diagnosed multiple myeloma," Blood, vol. 106, no. 7, pp. 2276-2279, 2005.

[11] P. G. Richardson, P. Sonneveld, M. W. Schuster et al., "Bortezomib or high-dose dexamethasone for relapsed multiple myeloma," The New England Journal of Medicine, vol. 352, no. 24, pp. 2487-2498, 2005.

[12] J. F. San Miguel, R. Schlag, N. K. Khuageva et al., "Bortezomib plus melphalan and prednisone for initial treatment of multiple myeloma," The New England Journal of Medicine, vol. 359, no. 9, pp. 906-917, 2008.

[13] A. Palumbo, S. Bringhen, T. Caravita et al., "Oral melphalan and prednisone chemotherapy plus thalidomide compared with melphalan and prednisone alone in elderly patients with multiple myeloma: randomised controlled trial," The Lancet, vol. 367, no. 9513, pp. 825-831, 2006.

[14] B. Barlogie, E. Anaissie, F. van Rhee et al., "Reiterative survival analyses of total therapy 2 for multiple myeloma elucidate follow-up time dependency of prognostic variables and treatment arms," Journal of Clinical Oncology, vol. 28, no. 18, pp. 3023-3027, 2010.

[15] D. M. Weber, C. Chen, R. Niesvizky et al., "Lenalidomide plus dexamethasone for relapsed multiple myeloma in North America," The New England Journal of Medicine, vol. 357, no. 21, pp. 2133-2142, 2007.

[16] M. Dimopoulos, A. Spencer, M. Attal et al., "Lenalidomide plus dexamethasone for relapsed or refractory multiple myeloma," The New England Journal of Medicine, vol. 357, no. 21, pp. 21232132, 2007.

[17] S. K. Kumar, S. V. Rajkumar, A. Dispenzieri et al., "Improved survival in multiple myeloma and the impact of novel therapies," Blood, vol. 111, no. 5, pp. 2516-2520, 2008.

[18] S. K. Kumar, J. H. Lee, J. J. Lahuerta et al., "Risk of progression and survival in multiple myeloma relapsing after therapy with IMiDs and bortezomib: a multicenter international myeloma working group study," Leukemia, vol. 26, no. 1, pp. 149-157, 2011.

[19] W. M. Kuehl and P. L. Bergsagel, "Multiple myeloma: evolving genetic events and host interactions," Nature Reviews Cancer, vol. 2, no. 3, pp. 175-187, 2002.

[20] S. V. Rajkumar, R. Fonseca, G. W. Dewald et al., "Cytogenetic abnormalities correlate with the plasma cell labeling index and extent of bone marrow involvement in myeloma," Cancer Genetics and Cytogenetics, vol. 113, no. 1, pp. 73-77, 1999.

[21] G. J. Ahmann, S. M. Jalal, A. L. Juneau et al., "A novel three-color, clone-specific fluorescence in situ hybridization procedure for monoclonal gammopathies," Cancer Genetics and Cytogenetics, vol. 101, no. 1, pp. 7-11, 1998.

[22] H. Avet-Loiseau, T. Facon, A. Daviet et al., "14q32 translocations and monosomy 13 observed in monoclonal gammopathy of undetermined significance delineate a multistep process for the oncogenesis of multiple myeloma. Intergroupe Francophone du Myélome," Cancer Research, vol. 59, no. 18, pp. 4546-4550, 1999.

[23] J. R. Sawyer, J. L. Lukacs, E. L. Thomas et al., "Multicolour spectral karyotyping identifies new translocations and a recurring pathway for chromosome loss in multiple myeloma," British Journal of Haematology, vol. 112, no. 1, pp. 167-174, 2001.
[24] P. L. Bergsagel and W. M. Kuehl, "Chromosome translocations in multiple myeloma," Oncogene, vol. 20, no. 40, pp. 5611-5622, 2001.

[25] T. Hideshima, P. L. Bergsagel, W. M. Kuehl, and K. C. Anderson, "Advances in biology of multiple myeloma: clinical applications," Blood, vol. 104, no. 3, pp. 607-618, 2004.

[26] G. Teoh and K. C. Anderson, "Interaction of tumor and host cells with adhesion and extracellular matrix molecules in the development of multiple myeloma," Hematology/Oncology Clinics of North America, vol. 11, no. 1, pp. 27-42, 1997.

[27] T. Hideshima, D. Chauhan, R. Schlossman, P. Richardson, and K. C. Anderson, "The role of tumor necrosis factor $\alpha$ in the pathophysiology of human multiple myeloma: therapeutic applications," Oncogene, vol. 20, no. 33, pp. 4519-4527, 2001.

[28] A. Lichtenstein, Y. Tu, C. Fady, R. Vescio, and J. Berenson, "Interleukin-6 inhibits apoptosis of malignant plasma cells," Cellular Immunology, vol. 162, no. 2, pp. 248-255, 1995.

[29] D. Chauhan, S. Kharbanda, A. Ogata et al., "Interleukin6 inhibits Fas-induced apoptosis and stress-activated protein kinase activation in multiple myeloma cells," Blood, vol. 89, no. 1, pp. 227-234, 1997.

[30] A. Ogata, D. Chauhan, G. Teoh et al., "IL-6 triggers cell growth via the ras-dependent mitogen-activated protein kinase cascade," Journal of Immunology, vol. 159, no. 5, pp. 2212-2221, 1997.

[31] Y. Tu, A. Gardner, and A. Lichtenstein, “The phosphatidylinositol 3-kinase/AKT kinase pathway in multiple myeloma plasma cells: roles in cytokine-dependent survival and proliferative responses," Cancer Research, vol. 60, no. 23, pp. 6763-6770, 2000.

[32] T. Hideshima, N. Nakamura, D. Chauhan, and K. C. Anderson, "Biologic sequelae of interleukin-6 induced PI3-K/Akt signaling in multiple myeloma," Oncogene, vol. 20, no. 42, pp. 59916000, 2001.

[33] G. G. Freund, D. T. Kulas, and R. A. Mooney, "Insulin and IGF1 increase mitogenesis and glucose metabolism in the multiple myeloma cell line, RPMI 8226," The Journal of Immunology, vol. 151, no. 4, pp. 1811-1820, 1993.

[34] M. Ogawa, T. Nishiura, K. Oritani et al., "Cytokines prevent dexamethasone-induced apoptosis via the activation of mitogen-activated protein kinase and phosphatidylinositol 3kinase pathways in a new multiple myeloma cell line," Cancer Research, vol. 60, no. 15, pp. 4262-4269, 2000.

[35] C. S. Mitsiades, N. Mitsiades, V. Poulaki et al., "Activation of NF-KB and upregulation of intracellular anti-apoptotic proteins via the IGF-1/Akt signaling in human multiple myeloma cells: therapeutic implications," Oncogene, vol. 21, no. 37, pp. 56735683, 2002.

[36] A.-T. Brenne, T. B. Ro, A. Waage, A. Sundan, M. Borset, and H. Hjorth-Hansen, "Interleukin-21 is a growth and survival factor for human myeloma cells," Blood, vol. 99, no. 10, pp. 3756-3762, 2002.

[37] K. Podar, Y.-T. Tai, F. E. Davies et al., "Vascular endothelial growth factor triggers signaling cascades mediating multiple myeloma cell growth and migration," Blood, vol. 98, no. 2, pp. 428-435, 2001.

[38] M. Ferlin, N. Noraz, C. Hertogh et al., "Insulin-like growth factor induces the survival and proliferation of myeloma cells through an interleukin-6-independent transduction pathway," British Journal of Haematology, vol. 111, no. 2, pp. 626-634, 2000.

[39] Y.-W. Qiang, E. Kopantzev, and S. Rudikoff, "Insulinlike growth factor-I signaling in multiple myeloma: downstream elements, 
functional correlates, and pathway cross-talk," Blood, vol. 99, no. 11, pp. 4138-4146, 2002.

[40] K. Podar, Y.-T. Tai, B. K. Lin et al., "Vascular endothelial growth factor-induced migration of multiple myeloma cells is associated with $\beta 1$ integrin- and phosphatidylinositol 3-kinasedependent PKC $\alpha$ activation," The Journal of Biological Chemistry, vol. 277, no. 10, pp. 7875-7881, 2002.

[41] T. Hideshima, D. Chauhan, T. Hayashi et al., "The biological sequelae of stromal cell-derived factor- $1 \alpha$ in multiple myeloma," Molecular Cancer Therapeutics, vol. 1, no. 7, pp. 539-544, 2002.

[42] M. E. Keir, M. J. Butte, G. J. Freeman, and A. H. Sharpe, "PD1 and its ligands in tolerance and immunity," Annual Review of Immunology, vol. 26, pp. 677-704, 2008.

[43] J. L. Riley, "PD-1 signaling in primary T cells," Immunological Reviews, vol. 229, no. 1, pp. 114-125, 2009.

[44] M. Quigley, F. Pereyra, B. Nilsson et al., "Transcriptional analysis of $\mathrm{HIV}$-specific $\mathrm{CD}^{+}{ }^{+} \mathrm{T}$ cells shows that $\mathrm{PD}-1$ inhibits T cell function by upregulating BATF,' Nature Medicine, vol. 16, no. 10, pp. 1147-1151, 2010.

[45] Y. Iwai, M. Ishida, Y. Tanaka, T. Okazaki, T. Honjo, and N. Minato, "Involvement of PD-L1 on tumor cells in the escape from host immune system and tumor immunotherapy by PD-L1 blockade," Proceedings of the National Academy of Sciences of the United States of America, vol. 99, no. 19, pp. 12293-12297, 2002.

[46] J. Liu, A. Hamrouni, D. Wolowiec et al., "Plasma cells from multiple myeloma patients express B7-H1 (PD-L1) and increase expression after stimulation with IFN- $\gamma$ and TLR ligands via a MyD88-, TRAF6-, and MEK-dependent pathway,' Blood, vol. 110, no. 1, pp. 296-304, 2007.

[47] D. M. Benson Jr., C. E. Bakan, A. Mishra et al., “The PD-1/PD-L1 axis modulates the natural killer cell versus multiple myeloma effect: a therapeutic target for CT-011, a novel monoclonal antiPD-1 antibody," Blood, vol. 116, no. 13, pp. 2286-2294, 2010.

[48] W. H. D. Hallett, W. Jing, W. R. Drobyski, and B. D. Johnson, "Immunosuppressive effects of multiple myeloma are overcome by PD-L1 blockade," Biology of Blood and Marrow Transplantation, vol. 17, no. 8, pp. 1133-1145, 2011.

[49] M. V. Iorio and C. M. Croce, "MicroRNAs in cancer: small molecules with a huge impact," Journal of Clinical Oncology, vol. 27, no. 34, pp. 5848-5856, 2009.

[50] A. Al Masri, T. Price-Troska, M. Chesi et al., "MicroRNA expression analysis in multiple myeloma," Blood, vol. 106, p. 1554, 2005.

[51] Y. Zhoua, L. Chena, B. Barlogiea et al., "High-risk myeloma is associated with global elevation of miRNAs and overexpression of EIF2C2/AGO2," Proceedings of the National Academy of Sciences of the United States of America, vol. 107, no. 17, pp. 79047909, 2010.

[52] M. Bakkus, S. Dujardin, I. Van Riet, and M. De Waele, "MicroRNA expression analysis in multiple myeloma plasma cells and cell lines by a quantitative real-time PCR approach," Blood, vol. 110, p. 2472, 2007.

[53] D. Löffler, K. Brocke-Heidrich, G. Pfeifer et al., "Interleukin6-dependent survival of multiple myeloma cells involves the Stat3-mediated induction of microRNA-21 through a highly conserved enhancer," Blood, vol. 110, no. 4, pp. 1330-1333, 2007.

[54] D. Ronchetti, M. Lionetti, L. Mosca et al., "An integrative genomic approach reveals coordinated expression of intronic miR-335, miR-342, and miR-561 with deregulated host genes in multiple myeloma," BMC Medical Genomics, vol. 1, article 37, 2008.
[55] F. Pichiorri, S.-S. Suh, M. Ladetto et al., "MicroRNAs regulate critical genes associated with multiple myeloma pathogenesis," Proceedings of the National Academy of Sciences of the United States of America, vol. 105, no. 35, pp. 12885-12890, 2008.

[56] L. Chen, C. Li, R. Zhang et al., "MiR-17-92 cluster microRNAs confers tumorigenicity in multiple myeloma," Cancer Letters, vol. 309, no. 1, pp. 62-70, 2011.

[57] Y.-K. Zhang, H. Wang, Y. Leng et al., "Overexpression of microRNA-29b induces apoptosis of multiple myeloma cells through down regulating Mcl-1," Biochemical and Biophysical Research Communications, vol. 414, no. 1, pp. 233-239, 2011.

[58] M. Gururajan, C. L. Haga, S. Das et al., "MicroRNA 125b inhibition of B cell differentiation in germinal centers," International Immunology, vol. 22, no. 7, pp. 583-592, 2010.

[59] A. F. Kisselev and A. L. Goldberg, "Proteasome inhibitors: from research tools to drug candidates," Chemistry \& Biology, vol. 8, no. 8, pp. 739-758, 2001.

[60] T. Hideshima, P. Richardson, D. Chauhan et al., "The proteasome inhibitor PS-341 inhibits growth, induces apoptosis, and overcomes drug resistance in human multiple myeloma cells," Cancer Research, vol. 61, no. 7, pp. 3071-3076, 2001.

[61] N. Mitsiades, C. S. Mitsiades, V. Poulaki et al., "Molecular sequelae of proteasome inhibition in human multiple myeloma cells," Proceedings of the National Academy of Sciences of the United States of America, vol. 99, no. 22, pp. 14374-14379, 2002.

[62] J. L. Harousseau, C. Mathiot, M. Attal et al., "Bortezomib/ dexamethasone versus VAD as induction prior to autologous stem cell transplantation (ASCT) in previously untreated multiple myeloma (MM): updated data from IFM 2005/01 trial," Journal of Clinical Oncology, vol. 26, abstract 8505, p. 455s, 2008.

[63] M. Cavo, P. Tacchetti, F. Patriarca et al., "Superior complete response rate and progression-free survival after autologous transplantation with upfront velcade-thalidomidedexamethasone compared with thalidomide-dexamethasone in newly diagnosed multiple myeloma," Blood, vol. 112, abstract 158, p. 65a, 2008.

[64] B. Barlogie, E. Anaissie, F. van Rhee et al., "Incorporating bortezomib into upfront treatment for multiple myeloma: early results of total therapy 3," British Journal of Haematology, vol. 138, no. 2, pp. 176-185, 2007.

[65] B. Barlogie, E. F. Anaissie, J. D. Shaughnessy et al., "Ninety percent sustained complete response (CR) rate projected 4 years after onset of CR in gene expression profiling (GEP)-defined low-risk multiple myeloma (MM) treated with Total Therapy 3 (TT3): basis for GEP-risk-adapted TT4 and TT5," Blood, vol. 112, abstract 162, pp. 66a-67a, 2008.

[66] B. Barlogie, E. Anaissie, J. D. Shaughnessy Jr. et al., "Phase II study of total therapy 3 (TT3) with added bortezomib (v) for multiple myeloma (MM)," Journal of Clinical Oncology, vol. 25, supplement 18, abstract 8020, 2007.

[67] A. Palumbo, P. Falco, F. Gay et al., "Bortezomib-doxorubicindexamethasone as induction prior to reduced intensity autologous transplantation followed by lenalidomide as consolidation/maintenance in elderly untreated myeloma patients," Blood, vol. 112, abstract 159, p. 65a, 2008.

[68] M.-V. Mateos, P. G. Richardson, R. Schlag et al., "Bortezomib plus melphalan and prednisone compared with melphalan and prednisone in previously untreated multiple myeloma: updated follow-up and impact of subsequent therapy in the phase III VISTA trial," Journal of Clinical Oncology, vol. 28, no. 13, pp. 2259-2266, 2010. 
[69] M. V. Mateos, A. Oriol, J. Martinez et al., "Bortezomib (VELCADE)-melphalan prednisone (VMP) versus VELCADEthalidomide-prednisone (VTP) in elderly untreated multiple myeloma (MM) patients," Haematologica, vol. 94, no. 190, abstract 0471, 2009.

[70] A. Paumbo, S. Bringhen, D. Rossi et al., "Bortezomib, melphalan, prednisone and thalidomide (VMPT) versus bortezomib, melphalan and prednisone (VMP) in elderly newly diagnosed myeloma patients: a prospective, randomized, phase III study," Haematologica, vol. 94, abstract 0472, pp. 190-191, 2009.

[71] T. Facon, J. Y. Mary, C. Hulin et al., "Melphalan and prednisone plus thalidomide versus melphalan and prednisone alone or reduced-intensity autologous stem cell transplantation in elderly patients with multiple myeloma (IFM 99-06): a randomised trial," The Lancet, vol. 370, no. 9594, pp. 1209-1218, 2007.

[72] P. G. Richardson, P. Sonneveld, M. Schuster et al., "Extended follow-up of a phase 3 trial in relapsed multiple myeloma: final time-to-event results of the APEX trial," Blood, vol. 110, no. 10, pp. 3557-3560, 2007.

[73] A. Palumbo, F. Gay, S. Bringhen et al., "Bortezomib, doxorubicin and dexamethasone in advanced multiple myeloma," Annals of Oncology, vol. 19, no. 6, pp. 1160-1165, 2008.

[74] W.-C. Yang and S.-F. Lin, "Achieving complete response in multiple myeloma: do we need to change the definition?" Journal of Internal Medicine of Taiwan, vol. 22, no. 4, pp. 266277, 2011.

[75] E. P. Sampaio, E. N. Sarno, R. Galilly, Z. A. Cohn, and G. Kaplan, "Thalidomide selectively inhibits tumor necrosis factor $\alpha$ production by stimulated human monocytes," The Journal of Experimental Medicine, vol. 173, no. 3, pp. 699-703, 1991.

[76] A. L. Moreira, E. P. Sampaio, A. Zmuidzinas, P. Frindt, K. A. Smith, and G. Kaplan, "Thalidomide exerts its inhibitory action on tumor necrosis factor $\alpha$ by enhancing mRNA degradation," The Journal of Experimental Medicine, vol. 177, no. 6, pp. 16751680, 1993.

[77] R. J. D’Amato, M. S. Loughnan, E. Flynn, and J. Folkman, "Thalidomide is an inhibitor of angiogenesis," Proceedings of the National Academy of Sciences of the United States of America, vol. 91, no. 9, pp. 4082-4085, 1994.

[78] C. S. Mitsiades, S. P. Treon, N. Mitsiades et al., “TRAIL/Apo2L ligand selectively induces apoptosis and overcomes drug resistance in multiple myeloma: therapeutic applications," Blood, vol. 98, no. 3, pp. 795-804, 2001.

[79] N. Mitsiades, C. S. Mitsiades, V. Poulaki et al., "Apoptotic signaling induced by immunomodulatory thalidomide analogs in human multiple myeloma cells: therapeutic implications," Blood, vol. 99, no. 12, pp. 4525-4530, 2002.

[80] T. Hideshima, D. Chauhan, Y. Shima et al., "Thalidomide and its analogs overcome drug resistance of human multiple myeloma cells to conventional therapy," Blood, vol. 96, no. 9, pp. 29432950, 2000.

[81] D. Gupta, S. P. Treon, Y. Shima et al., "Adherence of multiple myeloma cells to bone marrow stromal cells upregulates vascular endothelial growth factor secretion: therapeutic applications," Leukemia, vol. 15, no. 12, pp. 1950-1961, 2001.

[82] F. E. Davies, N. Raje, T. Hideshima et al., "Thalidomide and immunomodulatory derivatives augment natural killer cell cytotoxicity in multiple myeloma," Blood, vol. 98, no. 1, pp. 210216, 2001.

[83] H. M. Lokhorst, B. Van Der Holt, S. Zweegman et al., "A randomized phase 3 study on the effect of thalidomide combined with adriamycin, dexamethasone, and high-dose melphalan, followed by thalidomide maintenance in patients with multiple myeloma," Blood, vol. 115, no. 6, pp. 1113-1120, 2010.

[84] S. V. Rajkumar, E. Blood, D. Vesole, R. Fonseca, and P. R. Greipp, "Phase III clinical trial of thalidomide plus dexamethasone compared with dexamethasone alone in newly diagnosed multiple myeloma: a clinical trial coordinated by the eastern cooperative oncology group," Journal of Clinical Oncology, vol. 24, no. 3, pp. 431-436, 2006.

[85] K. Zervas, D. Mihou, E. Katodritou et al., "VAD-doxil versus VAD-doxil plus thalidomide as initial treatment for multiple myeloma: results of a multicenter randomized trial of the Greek myeloma study group," Annals of Oncology, vol. 18, no. 8, pp. 1369-1375, 2007.

[86] S. V. Rajkumar, S. Jacobus, N. Callander et al., "Randomized trial of lenalidomide plus high-dose dexamethasone versus lenalidomide plus low-dose dexamethasone in newly diagnosed myeloma (E4A03), a trial coordinated by the Eastern Cooperative Oncology Group: analysis of response, survival, and outcome with," Journal of Clinical Oncology, vol. 26, no. 15, supplement, abstract 8504, 2008.

[87] B. Barlogie, M. Pineda-Roman, F. van Rhee et al., "Thalidomide arm of total therapy 2 improves complete remission duration and survival in myeloma patients with metaphase cytogenetic abnormalities," Blood, vol. 112, no. 8, pp. 3115-3121, 2008.

[88] A. Palumbo, S. Bringhen, A. M. Liberati et al., "Oral melphalan, prednisone, and thalidomide in elderly patients with multiple myeloma: updated results of a randomized controlled trial," Blood, vol. 112, no. 8, pp. 3107-3114, 2008.

[89] C. Hulin, T. Facon, P. Rodon et al., "Efficacy of melphalan and prednisone plus thalidomide in patients older than 75 years with newly diagnosed multiple myeloma: IFM 01/01 trial," Journal of Clinical Oncology, vol. 27, no. 22, pp. 3664-3670, 2009.

[90] P. Wijermans, M. Schaafsma, Y. Van Norden et al., "Melphalan + prednisone versus melphalan + prednisone + thalidomide in induction therapy for multiple myeloma in elderly patients: final analysis of the Dutch Cooperative Group HOVON 49 study," Blood, vol. 112, abstract 649, pp. 241a-242a, 2008.

[91] A. Waage, P. Gimsing, G. Juliusson et al., "Melphalan prednisone-thalidomide to newly diagnosed patients with multiple myeloma: a placebo controlled randomized phase 3 trial," Blood, vol. 110, abstract 78, p. 32a, 2007.

[92] H. Ludwig, R. Hajek, E. Tóthová et al., “Thalidomide-dexamethasone compared with melphalan-prednisolone in elderly patients with multiple myeloma," Blood, vol. 113, no. 15, pp. 3435-3442, 2009.

[93] S. V. Rajkumar, L. Rosiñol, M. Hussein et al., "Multicenter, randomized, double-blind, placebo-controlled study of thalidomide plus dexamethasone compared with dexamethasone as initial therapy for newly diagnosed multiple myeloma," Journal of Clinical Oncology, vol. 26, no. 13, pp. 2171-2177, 2008.

[94] J. A. Zonder, J. Crowley, M. A. Hussein et al., "Superiority of lenalidomide (Len) plus high-dose dexamethasone (HD) compared to HD alone as treatment of newly-diagnosed multiple myeloma (NDMM): results of the randomized, double-blinded, placebo-controlled SWOG trial S0232," Blood, vol. 110, no. 32, abstract 77, 2007.

[95] A. Palumbo, P. Falco, P. Corradini et al., "Melphalan, prednisone, and lenalidomide treatment for newly diagnosed myeloma: a report from the GIMEMA-Italian Multiple Myeloma Network," Journal of Clinical Oncology, vol. 25, no. 28, pp. 4459-4465, 2007. 
[96] M. Offidani, L. Corvatta, N. M. Piersantelli et al., "Thalidomide, dexamethasone and pegylated liposomal doxorubicin (ThaDD) for newly diagnosed multiple myeloma patients over 65 years," Blood, vol. 108, no. 7, pp. 2159-2164, 2006.

[97] J. S. Miguel, K. Weisel, P. Moreau et al., "Pomalidomide plus lowdose dexamethasone versus high-dose dexamethasone alone for patients with relapsed and refractory multiple myeloma (MM-003): a randomised, open-label, phase 3 trial," The Lancet Oncology, vol. 14, no. 11, pp. 1055-1066, 2013.

[98] P. G. Richardson, E. Weller, S. Lonial et al., "Lenalidomide, bortezomib, and dexamethasone combination therapy in patients with newly diagnosed multiple myeloma," Blood, vol. 116, no. 5, pp. 679-686, 2010.

[99] A. Covelli, "Modulation of multidrug resistance (MDR) in hematological malignancies," Annals of Oncology, vol. 10, no. 6, pp. S53-S59, 1999.

[100] H. Schwarzenbach, "Expression of MDR1/P-glycoprotein, the multidrug resistance protein MRP, and the lung-resistance protein LRP in multiple myeloma," Medical Oncology, vol. 19, no. 2, pp. 87-104, 2002.

[101] G. Buda, D. Ricci, C. C. Huang et al., "Polymorphisms in the multiple drug resistance protein 1 and in P-glycoprotein 1 are associated with time to event outcomes in patients with advanced multiple myeloma treated with bortezomib and pegylated liposomal doxorubicin," Annals of Hematology, vol. 89, no. 11, pp. 1133-1140, 2010.

[102] T. Hideshima and K. C. Anderson, "Molecular mechanisms of novel therapeutic approaches for multiple myeloma," Nature Reviews Cancer, vol. 2, no. 12, pp. 927-937, 2002.

[103] J. S. Damiano, A. E. Cress, L. A. Hazlehurst, A. A. Shtil, and W. S. Dalton, "Cell adhesion mediated drug resistance (CAM-DR): role of integrins and resistance to apoptosis in human myeloma cell lines," Blood, vol. 93, no. 5, pp. 1658-1667, 1999.

[104] L. A. Hazlehurst, J. S. Damiano, I. Buyuksal, W. J. Pledger, and W. S. Dalton, "Adhesion to fibronectin via $\beta 1$ integrins regulates p $27^{k i p 1}$ levels and contributes to cell adhesion mediated drug resistance (CAM-DR)," Oncogene, vol. 19, no. 38, pp. 4319-4327, 2000.

[105] R. Catlett-Falcone, T. H. Landowski, M. M. Oshiro et al., "Constitutive activation of Stat3 signaling confers resistance to apoptosis in human U266 myeloma cells," Immunity, vol. 10, no. 1, pp. 105-115, 1999.

[106] W. S. Dalton and R. Jove, "Drug resistance in multiple myeloma: approaches to circumvention," Seminars in Oncology, vol. 26, no. 5, pp. 23-27, 1999.

[107] L.-H. Wei, M.-L. Kuo, C.-A. Chen et al., “The anti-apoptotic role of interleukin- 6 in human cervical cancer is mediated by upregulation of Mcl-1 through a PI 3-K/Akt pathway," Oncogene, vol. 20, no. 41, pp. 5799-5809, 2001.

[108] P. K. Epling-Burnette, B. Zhong, F. Bai et al., "Cooperative regulation of Mcl-1 by Janus kinase/STAT and phosphatidylinositol 3-kinase contribute to granulocyte-macrophage colonystimulating factor-delayed apoptosis in human neutrophils," The Journal of Immunology, vol. 166, no. 12, pp. 7486-7495, 2001.

[109] D. Chauhan, T. Hideshima, P. Pandey et al., "RAFTK/PYK2dependent and independent apoptosis in multiple myeloma cells," Oncogene, vol. 18, no. 48, pp. 6733-6740, 1999.

[110] N. Mitsiades, C. S. Mitsiades, V. Poulaki et al., "Biologic sequelae of nuclear factor- $\kappa$ B blockade in multiple myeloma: therapeutic applications," Blood, vol. 99, no. 11, pp. 4079-4086, 2002.
[111] T. Hideshima, D. Chauhan, P. Richardson et al., "NF- $\kappa$ B as a therapeutic target in multiple myeloma," The Journal of Biological Chemistry, vol. 277, no. 19, pp. 16639-16647, 2002.

[112] L. Xie, R. Jing, J. Qi, Z. Lin, and S. Ju, "Drug resistance-related microRNAs in hematological malignancies: translating basic evidence into therapeutic strategies," Blood Reviews, vol. 29, no. 1, pp. 33-44, 2015.

[113] J. Ma, C. Dong, and C. Ji, "MicroRNA and drug resistance," Cancer Gene Therapy, vol. 17, no. 8, pp. 523-531, 2010.

[114] A. M. Roccaro, A. Sacco, B. Thompson et al., "MicroRNAs $15 \mathrm{a}$ and 16 regulate tumor proliferation in multiple myeloma," Blood, vol. 113, no. 26, pp. 6669-6680, 2009.

[115] L. Benetatos and G. Vartholomatos, "Deregulated microRNAs in multiple myeloma," Cancer, vol. 118, no. 4, pp. 878-887, 2012.

[116] P. Neri, K. Gratton, L. Ren et al., "miRNA expression in multiple myeloma as predictive model of response to bortezomib," Blood, vol. 114, p. 4918, 2009.

[117] X. Wang, C. Li, S. Ju, Y. Wang, H. Wang, and R. Zhong, "Myeloma cell adhesion to bone marrow stromal cells confers drug resistance by microRNA-21 up-regulation," Leukemia \& Lymphoma, vol. 52, no. 10, pp. 1991-1998, 2011.

[118] E. Leone, E. Morelli, M. T. Di Martino et al., "Targeting miR21 inhibits in vitro and in vivo multiple myeloma cell growth," Clinical Cancer Research, vol. 19, no. 8, pp. 2096-2106, 2013.

[119] N. Ahmad, S. Haider, S. Jagannathan, E. Anaissie, and J. J. Driscoll, "MicroRNA theragnostics for the clinical management of multiple myeloma," Leukemia, vol. 28, no. 4, pp. 732-738, 2014.

[120] S. Jagannathan, N. Vad, S. Vallabhapurapu, S. Vallabhapurapu, K. C. Anderson, and J. J. Driscoll, "MiR-29b replacement inhibits proteasomes and disrupts aggresome+autophagosome formation to enhance the antimyeloma benefit of bortezomib," Leukemia, vol. 29, no. 3, pp. 727-738, 2015.

[121] M. Milani, T. Rzymski, H. R. Mellor et al., “The role of ATF4 stabilization and autophagy in resistance of breast cancer cells treated with Bortezomib," Cancer Research, vol. 69, no. 10, pp. 4415-4423, 2009.

[122] J. D. Shaughnessy Jr., P. Qu, S. Usmani et al., "Pharmacogenomics of bortezomib test-dosing identifies hyperexpression of proteasome genes, especially PSMD4, as novel high-risk feature in myeloma treated with total therapy 3," Blood, vol. 118, no. 13, pp. 3512-3524, 2011.

[123] F. W. Cremer, J. Bila, I. Buck et al., "Delineation of distinct subgroups of multiple myeloma and a model for clonal evolution based on interphase cytogenetics," Genes Chromosomes and Cancer, vol. 44, no. 2, pp. 194-203, 2005.

[124] A. K. Stewart, H. Chang, S. Trudel et al., "Diagnostic evaluation of $\mathrm{t}(4 ; 14)$ in multiple myeloma and evidence for clonal evolution," Leukemia, vol. 21, no. 11, pp. 2358-2359, 2007.

[125] B. C. Baliga and S. Kumar, "Role of BCL-2 family of proteins in malignancy," Hematological Oncology, vol. 20, no. 2, pp. 63-74, 2002.

[126] H. Tamura, M. Ishibashi, T. Yamashita et al., "Marrow stromal cells induce B7-H1 expression on myeloma cells, generating aggressive characteristics in multiple myeloma," Leukemia, vol. 27, no. 2, pp. 464-472, 2013.

[127] K. Kuranda, C. Berthon, C. Dupont et al., "A subpopulation of malignant $\mathrm{CD} 34^{+} \mathrm{CD} 138^{+} \mathrm{B} 7-\mathrm{H} 1^{+}$plasma cells is present in multiple myeloma patients," Experimental Hematology, vol. 38, no. 2, pp. 124.e4-131.e4, 2010. 
[128] A. Sharabi and N. H. Ghera, "Breaking tolerance in a mouse model of multiple myeloma by chemoimmunotherapy," Advances in Cancer Research, vol. 107, pp. 1-37, 2010.

[129] M. Nojima, R. Maruyama, H. Yasui et al., "Genomic screening for genes silenced by DNA methylation revealed an association between RASD1 inactivation and dexamethasone resistance in multiple myeloma," Clinical Cancer Research, vol. 15, no. 13, pp. 4356-4364, 2009.

[130] B. Ewald, D. Sampath, and W. Plunkett, "Nucleoside analogs: molecular mechanisms signaling cell death," Oncogene, vol. 27, no. 50, pp. 6522-6537, 2008.

[131] T. R. Wilson, P. G. Johnston, and D. B. Longley, "Anti-apoptotic mechanisms of drug resistance in cancer," Current Cancer Drug Targets, vol. 9, no. 3, pp. 307-319, 2009.

[132] B. Rochat, "Importance of influx and efflux systems and xenobiotic metabolizing enzymes in intratumoral disposition of anticancer agents," Current Cancer Drug Targets, vol. 9, no. 5, pp. 652-674, 2009.

[133] C. Houde, Y. Li, L. Song et al., "Overexpression of the NOTCH ligand JAG2 in malignant plasma cells from multiple myeloma patients and cell lines," Blood, vol. 104, no. 12, pp. 3697-3704, 2004.

[134] F. Jundt, K. S. Pröbsting, I. Anagnostopoulos et al., "Jagged1induced Notch signaling drives proliferation of multiple myeloma cells," Blood, vol. 103, no. 9, pp. 3511-3515, 2004.

[135] P. W. B. Derksen, E. Tjin, H. P. Meijer et al., "Illegitimate WNT signaling promotes proliferation of multiple myeloma cells," Proceedings of the National Academy of Sciences of the United States of America, vol. 101, no. 16, pp. 6122-6127, 2004.

[136] Y.-W. Qiang, K. Walsh, L. Yao et al., "Wnts induce migration and invasion of myeloma plasma cells," Blood, vol. 106, no. 5 , pp. 1786-1793, 2005.

[137] C. D. Peacock, Q. Wang, G. S. Gesell et al., "Hedgehog signaling maintains a tumor stem cell compartment in multiple myeloma," Proceedings of the National Academy of Sciences of the United States of America, vol. 104, no. 10, pp. 4048-4053, 2007.

[138] C. A. Huff and W. Matsui, "Multiple myeloma cancer stem cells," Journal of Clinical Oncology, vol. 26, no. 17, pp. 2895-2900, 2008.

[139] W. Matsui, Q. Wang, J. P. Barber et al., "Clonogenic multiple myeloma progenitors, stem cell properties, and drug resistance," Cancer Research, vol. 68, no. 1, pp. 190-197, 2008.

[140] T. Ito, H. Ando, T. Suzuki et al., "Identification of a primary target of thalidomide teratogenicity," Science, vol. 327, no. 5971, pp. 1345-1350, 2010.

[141] A. L. Shaffer, N. C. T. Emre, L. Lamy et al., "IRF4 addiction in multiple myeloma," Nature, vol. 454, no. 7201, pp. 226-231, 2008.

[142] S. K. Kumar, M. Q. Lacy, S. R. Hayman et al., "Lenalidomide, cyclophosphamide and dexamethasone (CRd) for newly diagnosed multiple myeloma: results from a phase 2 trial," American Journal of Hematology, vol. 86, no. 8, pp. 640-645, 2011.

[143] A. Lopez-Girona, D. Heintel, L.-H. Zhang et al., "Lenalidomide downregulates the cell survival factor, interferon regulatory factor-4, providing a potential mechanistic link for predicting response," British Journal of Haematology, vol. 154, no. 3, pp. 325-336, 2011.

[144] Y. X. Zhu, E. Braggio, C.-X. Shi et al., "Cereblon expression is required for the antimyeloma activity of lenalidomide and pomalidomide," Blood, vol. 118, no. 18, pp. 4771-4779, 2011.

[145] A. Lopez-Girona, D. Mendy, T. Ito et al., "Cereblon is a direct protein target for immunomodulatory and antiproliferative activities of lenalidomide and pomalidomide," Leukemia, vol. 26, no. 11, pp. 2326-2335, 2012.
[146] A. Broyl, R. Kuiper, M. van Duin et al., "High cereblon expression is associated with better survival in patients with newly diagnosed multiple myeloma treated with thalidomide maintenance," Blood, vol. 121, no. 4, pp. 624-627, 2013.

[147] D. Heintel, A. Rocci, H. Ludwig et al., "High expression of cereblon $(\mathrm{CRBN})$ is associated with improved clinical response in patients with multiple myeloma treated with lenalidomide and dexamethasone," British Journal of Haematology, vol. 161, no. 5, pp. 695-700, 2013.

[148] Y.X. Zhu, E. Braggio, C.-X. Shi et al., "Identification of cereblonbinding proteins and relationship with response and survival after IMiDs in multiple myeloma," Blood, vol. 124, no. 4, pp. 536545, 2014.

[149] P. Neri, A. R. Belch, J. Johnson et al., "A miRNA risk score for the prediction of response to lenalidomide in multiple myeloma (MM) patients," ASH Annual Meeting Abstracts, vol. 118, no. 21, p. 987, 2011.

[150] A. Mahindra, J. Laubach, N. Raje, N. Munshi, P. G. Richardson, and $\mathrm{K}$. Anderson, "Latest advances and current challenges in the treatment of multiple myeloma," Nature Reviews Clinical Oncology, vol. 9, no. 3, pp. 135-143, 2012.

[151] D. Chauhan, A. V. Singh, M. Aujay et al., "A novel orally active proteasome inhibitor ONX 0912 triggers in vitro and in vivo cytotoxicity in multiple myeloma," Blood, vol. 116, no. 23, pp. 4906-4915, 2010.

[152] F. Parlati, S. J. Lee, M. Aujay et al., "Carfilzomib can induce tumor cell death through selective inhibition of the chymotrypsin-like activity of the proteasome," Blood, vol. 114, no. 16, pp. 3439-3447, 2009.

[153] J. L. Thompson, "Carfilzomib: a second-generation proteasome inhibitor for the treatment of relapsed and refractory multiple myeloma," The Annals of Pharmacotherapy, vol. 47, no. 1, pp. 5662, 2013.

[154] J. M. Steele, "Carfilzomib: a new proteasome inhibitor for relapsed or refractory multiple myeloma," Journal of Oncology Pharmacy Practice, vol. 19, no. 4, pp. 348-354, 2013.

[155] R. Vij, J. L. Kaufman, A. J. Jakubowiak et al., "Final results from the Bortezomib-naïve group of PX-171-004, a phase 2 study of single-agent carfilzomib in patients with relapsed and/or refractory MM," ASH Annual Meeting Abstracts, vol. 118, p. 813, 2011.

[156] US National Library of Medicine, "Carfilzomib and lenalidomide with dexamethasone combination in newly diagnosed, previously untreated multiple myeloma," ClinicalTrials.gov, 2011, https://www.clinicaltrials.gov/ct2/show/NCT01029054.

[157] Phase 3 Study With Carfilzomib and Dexamethasone Versus Velcade and Dexamethasone for Relapsed Multiple Myeloma Patients (ENDEAVOR), US National Library of Medicine, ClinicalTrials.gov, 2012, https://www.clinicaltrials.gov/ct2/ show/NCT01568866.

[158] D. Chauhan, Z. Tian, B. Zhou et al., "In vitro and in vivo selective antitumor activity of a novel orally bioavailable proteasome inhibitor MLN9708 against multiple myeloma cells," Clinical Cancer Research, vol. 17, no. 16, pp. 5311-5321, 2011.

[159] P. G. Richardson, R. Baz, L. Wang et al., "Investigational agent MLN9708, an oral proteasome inhibitor, in patients (Pts) with relapsed and/or refractory multiple myeloma (MM): results from the expansion cohorts of a phase 1 dose-escalation study," ASH Annual Meeting Abstracts, vol. 118, abstract 301, 2011.

[160] A Study of IXAZOMIB Administered in Combination With Lenalidomide and Low-Dose Dexamethasone in 
Patients With Newly Diagnosed Multiple Myeloma, US National Library of Medicine, ClinicalTrials.gov, 2011, https://clinicaltrials.gov/ct2/show/nct01217957.

[161] US National Library of Medicine, "Ixazomib in treating patients with relapsed multiple myeloma that is not refractory to bortezomib," ClinicalTrials.gov, 2011, https://clinicaltrials .gov/ct2/show/nct01415882.

[162] D. Chauhan, Z. Tian, B. Nicholson et al., "A small molecule inhibitor of ubiquitin-specific protease-7 induces apoptosis in multiple myeloma cells and overcomes bortezomib resistance," Cancer Cell, vol. 22, no. 3, pp. 345-358, 2012.

[163] P. G. Richardson, A. Spencer, P. Cannell et al., "Phase 1 clinical evaluation of twice-weekly marizomib (NPI-0052), a novel proteasome inhibitor, in patients with relapsed/refractory multiple myeloma (MM)," ASH Annual Meeting Abstracts, vol. 118, p. 302, 2011.

[164] A. V. Singh, M. Bandi, M. A. Aujay et al., "PR-924, a selective inhibitor of the immunoproteasome subunit LMP-7, blocks multiple myeloma cell growth both in vitro and in vivo," British Journal of Haematology, vol. 152, no. 2, pp. 155-163, 2011.

[165] M. Q. Lacy, S. R. Hayman, M. A. Gertz et al., "Pomalidomide (CC4047) plus low-dose dexamethasone as therapy for relapsed multiple myeloma," Journal of Clinical Oncology, vol. 27, no. 30, pp. 5008-5014, 2009.

[166] P. G. Richardson, D. Siegel, R. Baz et al., "Phase 1 study of pomalidomide MTD, safety, and efficacy in patients with refractory multiple myeloma who have received lenalidomide and bortezomib," Blood, vol. 121, no. 11, pp. 1961-1967, 2013.

[167] J. F. San Miguel, K. C. Weisel, K. W. Song et al., "Impact of prior treatment and depth of response on survival in MM003 , a randomized phase 3 study comparing pomalidomide plus low-dose dexamethasone versus high-dose dexamethasone in relapsed/refractory multiple myeloma," Haematologica, vol. 100, no. 10, pp. 1334-1339, 2015.

[168] D. Atanackovic, T. Luetkens, and N. Kröger, "Coinhibitory molecule PD-1 as a potential target for the immunotherapy of multiple myeloma," Leukemia, vol. 28, no. 5, pp. 993-1000, 2014.

[169] A. Ribas, F. S. Hodi, R. Kefford et al., "Efficacy and safety of the anti-PD-1 monoclonal antibody MK-3475 in 411 patients (pts) with melanoma (MEL)," Journal of Clinical Oncology, vol. 32, no. 5, supplement, abstract LBA9000, 2014.

[170] J. R. Brahmer, C. G. Drake, I. Wollner et al., "Phase I study of single-agent anti-programmed death-1 (MDX-1106) in refractory solid tumors: safety, clinical activity, pharmacodynamics, and immunologic correlates," Journal of Clinical Oncology, vol. 28, no. 19, pp. 3167-3175, 2010.

[171] S. L. Topalian, F. S. Hodi, J. R. Brahmer et al., "Safety, activity, and immune correlates of anti-PD-1 antibody in cancer," The New England Journal of Medicine, vol. 366, no. 26, pp. 24432454, 2012.

[172] Y. Tanaka and H. Okamura, "Anti-PD-1 antibody: basics and clinical application," Gan To Kagaku Ryoho, vol. 40, no. 9, pp. 1145-1149, 2013.

[173] J. R. Brahmer, S. S. Tykodi, L. Q. M. Chow et al., "Safety and activity of anti-PD-L1 antibody in patients with advanced cancer," The New England Journal of Medicine, vol. 366, no. 26, pp. 2455-2465, 2012.

[174] A. M. Lesokhin, S. M. Ansell, P. Armand et al., "Preliminary results of a phase I study of nivolumab (BMS-936558) in patients with relapsed or refractory lymphoid malignancies," Blood, vol. 124, p. 291, 2014.
[175] D. M.-Y. Sze, G. Giesajtis, R. D. Brown et al., "Clonal cytotoxic $\mathrm{T}$ cells are expanded in myeloma and reside in the $\mathrm{CD}^{+} \mathrm{CD}^{+} 7^{+} \mathrm{CD} 28^{-}$compartment," Blood, vol. 98, no. 9, pp. 2817-2827, 2001.

[176] H. Suen, D. E. Joshua, R. D. Brown et al., "Protective cytotoxic clonal T-cells in myeloma have the characteristics of telomereindependent senescence rather than an exhausted or anergic phenotype: implications for immunotherapy," Blood, vol. 124, no. 21, p. 3367, 2014.

[177] H. Suen, R. Brown, S. Yang, P. J. Ho, J. Gibson, and D. Joshua, "The failure of immune checkpoint blockade in multiple myeloma with PD-1 inhibitors in a phase 1 study," Leukemia, vol. 29, no. 7, pp. 1621-1622, 2015.

[178] D. W. Sherbenou, C. R. Behrens, Y. Su, J. L. Wolf, T. G. Martin III, and B. Liu, "The development of potential antibody-based therapies for myeloma," Blood Reviews, vol. 29, no. 2, pp. 81-91, 2015.

[179] T. Plesner, H. Lokhorst, P. Gimsing, H. Nahi, S. Lisby, and P. G. Richardson, "Daratumumab, a CD38 monoclonal antibody in patients with multiple myeloma-data from a dose-escalation phase I/II study," Blood, vol. 120, no. 21, abstract 73, 2012.

[180] T. G. Martin III, S. A. Strickland, M. Glenn, W. Zheng, N. Daskalakis, and J. R. Mikhael, "SAR650984, a CD38 monoclonal antibody in patients with selected CD38+ hematological malignancies-data from a dose-escalation phase I study," Blood, vol. 122, no. 21, abstract 284, 2013.

[181] US National Library of Medicine, "An efficacy and safety study of daratumumab in patients with multiple myeloma who have received at least 3 prior lines of therapy (including a proteasome inhibitor [PI] and immunomodulatory drug [IMiD]) or are double refractory to a PI and an IMiD," ClinicalTrials.gov, 2013, https://clinicaltrials.gov/ct2/show/NCT01985126.

[182] Daratumumab in Combination With Lenalidomide and Dexamethasone in Relapsed and Relapsed-refractory Multiple Myeloma, US National Library of Medicine, ClinicalTrials.gov, 2012, https://www.clinicaltrials.gov/ct2/show/NCT01615029.

[183] US National Library of Medicine, "SAR650984, lenalidomide, and dexamethasone in combination in RRMM patients," ClinicalTrials.gov, 2012, https://clinicaltrials.gov/ct2/show/ NCT01749969.

[184] Phase 1/2 Dose Escalation and Efficacy Study of AntiCD38 Monoclonal Antibody in Patients With Selected CD38+ Hematological Malignancies, US National Library of Medicine, ClinicalTrials.gov, 2010, https://clinicaltrials.gov/ ct2/show/NCT01084252.

[185] J. L. Kaufman, R. Niesvizky, E. A. Stadtmauer et al., "Phase I, multicentre, dose-escalation trial of monotherapy with milatuzumab (humanized anti-CD74 monoclonal antibody) in relapsed or refractory multiple myeloma," British Journal of Haematology, vol. 163, no. 4, pp. 478-486, 2013.

[186] M. Hussein, J. R. Berenson, R. Niesvizky et al., "A phase I multidose study of dacetuzumab (SGN-40; humanized anti-CD40 monoclonal antibody) in patients with multiple myeloma," Haematologica, vol. 95, no. 5, pp. 845-848, 2010.

[187] W. Bensinger, R. T. Maziarz, S. Jagannath et al., "A phase 1 study of lucatumumab, a fully human anti-CD40 antagonist monoclonal antibody administered intravenously to patients with relapsed or refractory multiple myeloma," British Journal of Haematology, vol. 159, no. 1, pp. 58-66, 2012.

[188] J. A. Zonder, A. F. Mohrbacher, S. Singhal et al., "A phase 1, multicenter, open-label, dose escalation study of elotuzumab in 
patients with advanced multiple myeloma," Blood, vol. 120, no. 3, pp. 552-559, 2012.

[189] S. Lonial, S. Jagannath, P. Moreau et al., "Phase (Ph) I/II study of elotuzumab (Elo) plus lenalidomide/dexamethasone (Len/dex) in relapsed/refractory multiple myeloma (RR MM): updated $\mathrm{Ph}$ II results and $\mathrm{Ph} \mathrm{I} / \mathrm{II}$ long-term safety," Journal of Clinical Oncology, vol. 31, abstract 8542, 2013, ASCO Meeting Abstract.

[190] S. Lonial, M. Dimopoulos, A. Palumbo et al., "Elotuzumab therapy for relapsed or refractory multiple myeloma," The New England Journal of Medicine, vol. 373, pp. 621-631, 2015.

[191] M. Q. Lacy, M. Alsina, R. Fonseca et al., "Phase I, pharmacokinetic and pharmacodynamic study of the anti-insulinlike growth factor type 1 receptor monoclonal antibody CP-751,871 in patients with multiple myeloma," Journal of Clinical Oncology, vol. 26, no. 19, pp. 3196-3203, 2008.

[192] P. Moreau, F. Cavallo, X. Leleu et al., "Phase i study of the anti insulin-like growth factor 1 receptor (IGF-1R) monoclonal antibody, AVE1642, as single agent and in combination with bortezomib in patients with relapsed multiple myeloma," Leukemia, vol. 25, no. 5, pp. 872-874, 2011.

[193] D. J. Kuhn, Z. Berkova, R. J. Jones et al., “Targeting the insulinlike growth factor-1 receptor to overcome bortezomib resistance in preclinical models of multiple myeloma," Blood, vol. 120, no. 16, pp. 3260-3270, 2012.

[194] H. C. T. Van Zaanen, H. M. Lokhorst, L. A. Aarden et al., "Chimaeric anti-interleukin 6 monoclonal antibodies in the treatment of advanced multiple myeloma: a phase I doseescalating study," British Journal of Haematology, vol. 102, no. 3, pp. 783-790, 1998.

[195] R. Kurzrock, P. M. Voorhees, C. Casper et al., "A phase I, open-label study of siltuximab, an anti-IL-6 monoclonal antibody, in patients with B-cell non-hodgkin lymphoma, multiple myeloma, or castleman disease," Clinical Cancer Research, vol. 19, no. 13, pp. 3659-3670, 2013.

[196] P. M. Voorhees, R. F. Manges, P. Sonneveld et al., "A phase 2 multicentre study of siltuximab, an anti-interleukin-6 monoclonal antibody, in patients with relapsed or refractory multiple myeloma," British Journal of Haematology, vol. 161, no. 3, pp. 357-366, 2013.

[197] S. Jagannath, A. Chanan-Khan, L. T. Heffner et al., "BT062, an antibody-drug conjugate directed against CD138, shows clinical activity in patients with relapsed or relapsed/refractory multiple myeloma," Blood, vol. 118, no. 21, abstract 305, 2011.

[198] K. R. Kelly, A. Chanan-Khan, G. Somlo et al., "Indatuximab ravtansine (BT062) in combination with lenalidomide and lowdose dexamethasone in patients with relapsed and/or refractory multiple myeloma: clinical activity in len/dex-refractory patients," Blood, vol. 122, no. 21, abstract 758, 2013.

[199] A. Chanan-Khan, J. L. Wolf, J. Garcia et al., "Efficacy analysis from phase I study of lorvotuzumab mertansine (IMGN901), used as mono-therapy, in patients with heavily pre-treated CD56-positive multiple myeloma-a preliminary efficacy analysis," Blood, vol. 116, no. 21, abstract 1962, 1962.

[200] P. Sapra, R. Stein, J. Pickett et al., "Anti-CD74 antibodydoxorubicin conjugate, IMMU-110, in a human multiple myeloma xenograft and in monkeys," Clinical Cancer Research, vol. 11, no. 14, pp. 5257-5264, 2005.

[201] K. Elkins, B. Zheng, M. Go et al., "FcRL5 as a target of antibodydrug conjugates for the treatment of multiple myeloma," Molecular Cancer Therapeutics, vol. 11, no. 10, pp. 2222-2232, 2012.

[202] K. L. Yong, F. M. Germaschewski, M. Rodriguez-Justo et al., "Evaluation of BCMA as a therapeutic target in multiple myeloma using an antibody-drug conjugate," Blood, vol. 122, no. 21, p. 4447, 2013.

[203] Y.-T. Tai, P. A. Mayes, C. Acharya et al., "Novel anti-B-cell maturation antigen antibody-drug conjugate (GSK2857916) selectively induces killing of multiple myeloma," Blood, vol. 123, no. 20, pp. 3128-3138, 2014.

[204] S. A. Rosenberg, N. P. Restifo, J. C. Yang, R. A. Morgan, and M. E. Dudley, "Adoptive cell transfer: a clinical path to effective cancer immunotherapy," Nature Reviews Cancer, vol. 8, no. 4, pp. 299-308, 2008.

[205] B. Jena, G. Dotti, and L. J. N. Cooper, "Redirecting T-cell specificity by introducing a tumor-specific chimeric antigen receptor," Blood, vol. 116, no. 7, pp. 1035-1044, 2010.

[206] E. Q. Han, X.-L. Li, C.-R. Wang, T.-F. Li, and S.-Y. Han, "Chimeric antigen receptor-engineered $\mathrm{T}$ cells for cancer immunotherapy: progress and challenges," Journal of Hematology and Oncology, vol. 6, article 47, 2013.

[207] M. Bachmann, M. Cartellieri, A. Feldmann et al., "Chimeric antigen receptor-engineered $\mathrm{T}$ cells for immunotherapy of cancer," Journal of Biomedicine and Biotechnology, vol. 2010, Article ID 956304, 13 pages, 2010.

[208] B. A. Irving and A. Weiss, "The cytoplasmic domain of the T cell receptor $\zeta$ chain is sufficient to couple to receptor-associated signal transduction pathways," Cell, vol. 64, no. 5, pp. 891-901, 1991.

[209] Z. Eshhar, T. Waks, G. Gross, and D. G. Schindler, "Specific activation and targeting of cytotoxic lymphocytes through chimeric single chains consisting of antibody-binding domains and the gamma or zeta subunits of the immunoglobulin and Tcell receptors," Proceedings of the National Academy of Sciences of the United States of America, vol. 90, no. 2, pp. 720-724, 1993.

[210] J. Chu, Y. Deng, D. M. Benson et al., "CS1-specific chimeric antigen receptor (CAR)-engineered natural killer cells enhance in vitro and in vivo antitumor activity against human multiple myeloma," Leukemia, vol. 28, no. 4, pp. 917-927, 2014.

[211] J. Chu, S. He, Y. Deng et al., "Genetic modification of T cells redirected toward CS1 enhances eradication of myeloma cells," Clinical Cancer Research, vol. 20, no. 15, pp. 3989-4000, 2014.

[212] J. Wijdenes, W. C. Vooijs, C. Clément et al., "A plasmocyte selective monoclonal antibody (B-B4) recognizes syndecan-1," British Journal of Haematology, vol. 94, no. 2, pp. 318-323, 1996.

[213] B. Guo, M. Chen, Q. Han et al., "CD138-directed adoptive immunotherapy of chimeric antigen receptor (CAR)-modified T cells for multiple myeloma," Journal of Cellular Immunotherapy, 2015.

[214] R. O. Carpenter, M. O. Evbuomwan, S. Pittaluga et al., "B-cell maturation antigen is a promising target for adoptive T-cell therapy of multiple myeloma," Clinical Cancer Research, vol. 19, no. 8, pp. 2048-2060, 2013.

[215] CART-19 for Multiple Myeloma, US National Library of Medicine, ClinicalTrials.gov, 2014, https://clinicaltrials.gov/ ct2/show/NCT02135406.

[216] X.-Y. Pei, Y. Dai, and S. Grant, "Synergistic induction of oxidative injury and apoptosis in human multiple myeloma cells by the proteasome inhibitor bortezomib and histone deacetylase inhibitors," Clinical Cancer Research, vol. 10, no. 11, pp. 38393852, 2004.

[217] T. Hideshima, P. G. Richardson, and K. C. Anderson, "Mechanism of action of proteasome inhibitors and deacetylase inhibitors and the biological basis of synergy in multiple myeloma," Molecular Cancer Therapeutics, vol. 10, no. 11, pp. 2034-2042, 2011. 
[218] T. Hideshima, J. E. Bradner, J. Wong et al., "Small-molecule inhibition of proteasome and aggresome function induces synergistic antitumor activity in multiple myeloma," Proceedings of the National Academy of Sciences of the United States of America, vol. 102, no. 24, pp. 8567-8572, 2005.

[219] L. Santo, T. Hideshima, A. L. Kung et al., "Role of selective HDAC6 inhibition on multiple myeloma bone disease," ASH Annual Meeting Abstracts, vol. 120, p. 328, 2012.

[220] P. de la Puente, B. Muz, F. Azab, M. Luderer, and A. K. Azab, "Molecularly targeted therapies in multiple myeloma," Leukemia Research and Treatment, vol. 2014, Article ID 976567, 8 pages, 2014.

[221] H. Younes, X. Leleu, E. Hatjiharissi et al., "Targeting the phosphatidylinositol 3-kinase pathway in multiple myeloma," Clinical Cancer Research, vol. 13, no. 13, pp. 3771-3775, 2007.

[222] J. A. Engelman, "Targeting PI3K signalling in cancer: opportunities, challenges and limitations," Nature Reviews Cancer, vol. 9, no. 8, pp. 550-562, 2009.

[223] T. Hideshima, L. Catley, H. Yasui et al., "Perifosine, an oral bioactive novel alkylphospholipid, inhibits Akt and induces in vitro and in vivo cytotoxicity in human multiple myeloma cells," Blood, vol. 107, no. 10, pp. 4053-4062, 2006.

[224] A. Jakubowiak, P. G. Richardson, T. Zimmerman et al., "Phase I results of perifosine (KRX-0401) in combination with lenalidomide and dexamethasone in patients with relapsed or refractory multiple myeloma (MM)," ASH Annual Meeting Abstracts, vol. 112, p. 3691, 2008.

[225] P. G. Richardson, J. Wolf, A. Jakubowiak et al., "Perifosine plus bortezomib and dexamethasone in patients with relapsed/refractory multiple myeloma previously treated with bortezomib: results of a multicenter phase I/II trial," Journal of Clinical Oncology, vol. 29, no. 32, pp. 4243-4249, 2011.

[226] I. M. Ghobrial, E. Weller, R. Vij et al., "Weekly bortezomib in combination with temsirolimus in relapsed or relapsed and refractory multiple myeloma: a multicentre, phase $1 / 2$, openlabel, dose-escalation study," The Lancet Oncology, vol. 12, no. 3, pp. 263-272, 2011.

[227] A. Guenther, P. Baumann, R. Burger et al., "Phase I/II study with single agent everolimus (RAD001) in patients with relapsed or refractory multiple myeloma," ASH Annual Meeting Abstracts, vol. 114, p. 3850, 2009.

[228] P. Baumann, S. Mandl-Weber, F. Oduncu, and R. Schmidmaier, "The novel orally bioavailable inhibitor of phosphoinositol3-kinase and mammalian target of rapamycin, NVP-BEZ235, inhibits growth and proliferation in multiple myeloma," Experimental Cell Research, vol. 315, no. 3, pp. 485-497, 2009.

[229] J. He, Z. Liu, Y. Zheng et al., "p38 MAPK in myeloma cells regulates osteoclast and osteoblast activity and induces bone destruction," Cancer Research, vol. 72, no. 24, pp. 6393-6402, 2012.

[230] S. Medicherla, M. Reddy, Y. M. Jing et al., "p38 $\alpha$-selective MAP kinase inhibitor reduces tumor growth in mouse xenograft models of multiple myeloma," Anticancer Research, vol. 28, no. 6, pp. 3827-3834, 2008.

[231] K. Ishitsuka, T. Hideshima, P. Neri et al., "p38 mitogen-activated protein kinase inhibitor LY2228820 enhances bortezomibinduced cytotoxicity and inhibits osteoclastogenesis in multiple myeloma; therapeutic implications," British Journal of Haematology, vol. 141, no. 5, pp. 598-606, 2008.

[232] M. J. Drysdale, P. A. Brough, A. Massey, M. R. Jensen, and J. Schoepfer, "Targeting Hsp90 for the treatment of cancer,"
Current Opinion in Drug Discovery and Development, vol. 9, no. 4, pp. 483-495, 2006.

[233] P. G. Richardson, A. A. Chanan-Khan, S. Lonial et al., "Tanespimycin and bortezomib combination treatment in patients with relapsed or relapsed and refractory multiple myeloma: results of a phase 1/2 study," British Journal of Haematology, vol. 153, no. 6, pp. 729-740, 2011.

[234] N. Takebe, P. J. Harris, R. Q. Warren, and S. P. Ivy, “Targeting cancer stem cells by inhibiting Wnt, Notch, and Hedgehog pathways," Nature Reviews Clinical Oncology, vol. 8, no. 2, pp. 97-106, 2011.

[235] V. Ramakrishnan, S. Ansell, J. Haug et al., "MRK003, a $\gamma$ secretase inhibitor exhibits promising in vitro pre-clinical activity in multiple myeloma and non-Hodgkin's lymphoma," Leukemia, vol. 26, no. 2, pp. 340-348, 2012.

[236] D. Xu, J. Hu, E. De Bruyne et al., "Dll1/Notch activation contributes to bortezomib resistance by upregulating CYP1A1 in multiple myeloma," Biochemical and Biophysical Research Communications, vol. 428, no. 4, pp. 518-524, 2012.

[237] S. Blotta, J. Jakubikova, T. Calimeri et al., "Canonical and noncanonical Hedgehog pathway in the pathogenesis of multiple myeloma," Blood, vol. 120, no. 25, pp. 5002-5013, 2012.

[238] N. Raje, S. Kumar, T. Hideshima et al., "Seliciclib (CYC202 or R-roscovitine), a small-molecule cyclin-dependent kinase inhibitor, mediates activity via down-regulation of Mcl-1 in multiple myeloma," Blood, vol. 106, no. 3, pp. 1042-1047, 2005.

[239] D. W. McMillin, J. Delmore, J. Negri et al., "Molecular and cellular effects of multi-targeted cyclin-dependent kinase inhibition in myeloma: biological and clinical implications," British Journal of Haematology, vol. 152, no. 4, pp. 420-432, 2011.

[240] G. Görgün, E. Calabrese, T. Hideshima et al., "A novel AuroraA kinase inhibitor MLN8237 induces cytotoxicity and cell-cycle arrest in multiple myeloma," Blood, vol. 115, no. 25, pp. 5202$5213,2010$.

[241] H. Walczak, R. E. Miller, K. Ariail et al., "Tumoricidal activity of tumor necrosis factor-related apoptosis-inducing ligand in vivo," Nature Medicine, vol. 5, no. 2, pp. 157-163, 1999.

[242] P. Balsas, N. López-Royuela, P. Galán-Malo, A. Anel, I. Marzo, and J. Naval, "Cooperation between Apo2L/TRAIL and bortezomib in multiple myeloma apoptosis," Biochemical Pharmacology, vol. 77, no. 5, pp. 804-812, 2009.

[243] A. Vacca and D. Ribatti, "Bone marrow angiogenesis in multiple myeloma," Leukemia, vol. 20, no. 2, pp. 193-199, 2006.

[244] H. M. Prince, D. Hönemann, A. Spencer et al., "Vascular endothelial growth factor inhibition is not an effective therapeutic strategy for relapsed or refractory multiple myeloma: a phase 2 study of pazopanib (GW786034)," Blood, vol. 113, no. 19, pp. 4819-4820, 2009.

[245] M. J. Kovacs, D. E. Reece, D. Marcellus et al., "A phase II study of ZD6474 (Zactima), a selective inhibitor of VEGFR and EGFR tyrosine kinase in patients with relapsed multiple myelomaNCIC CTG IND.145," Investigational New Drugs, vol. 24, no. 6, pp. 529-535, 2006.

[246] M. Zangari, E. Anaissie, A. Stopeck et al., "Phase II study of SU5416, a small molecule vascular endothelial growth factor tyrosine kinase receptor inhibitor, in patients with refractory multiple myeloma," Clinical Cancer Research, vol. 10, no. 1, pp. 88-95, 2004.

[247] Y. Alsayed, H. Ngo, J. Runnels et al., "Mechanisms of regulation of CXCR4/SDF-1 (CXCL12)-dependent migration and homing in multiple myeloma," Blood, vol. 109, no. 7, pp. 2708-2717, 2007. 
[248] A. K. Azab, J. M. Runnels, C. Pitsillides et al., "CXCR4 inhibitor AMD3100 disrupts the interaction of multiple myeloma cells with the bone marrow microenvironment and enhances their sensitivity to therapy," Blood, vol. 113, no. 18, pp. 4341-4351, 2009.

[249] I. Ghobrial, R. Banwait, A. K. Azab et al., "Phase I trial of plerixafor and bortezomib as a chemosensitization strategy in relapsed or relapsed/refractory multiple myeloma," ASH Annual Meeting Abstracts, vol. 116, p. 1943, 2010.

[250] D. Chauhan, G. Li, K. Podar et al., “Targeting mitochondria to overcome conventional and bortezomib/proteasome inhibitor PS-341 resistance in multiple myeloma (MM) cells," Blood, vol. 104, no. 8, pp. 2458-2466, 2004. 


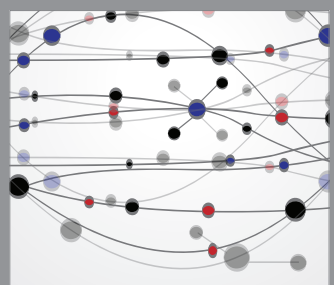

The Scientific World Journal
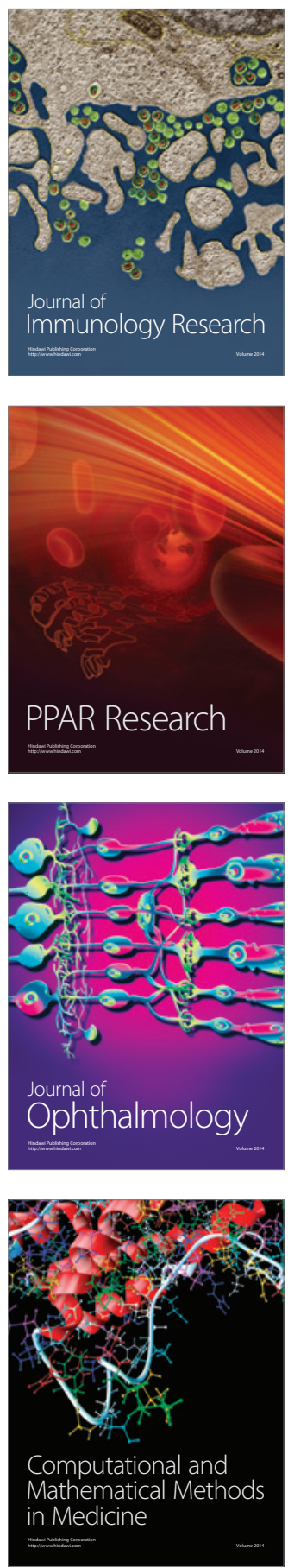

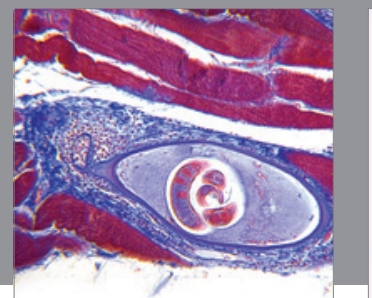

Gastroenterology

Research and Practice
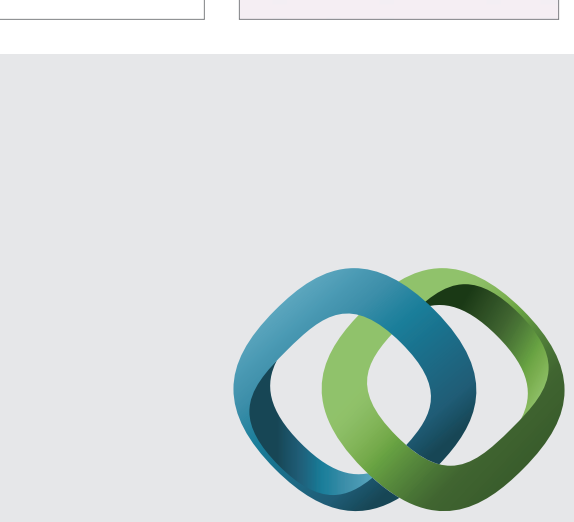

\section{Hindawi}

Submit your manuscripts at

http://www.hindawi.com
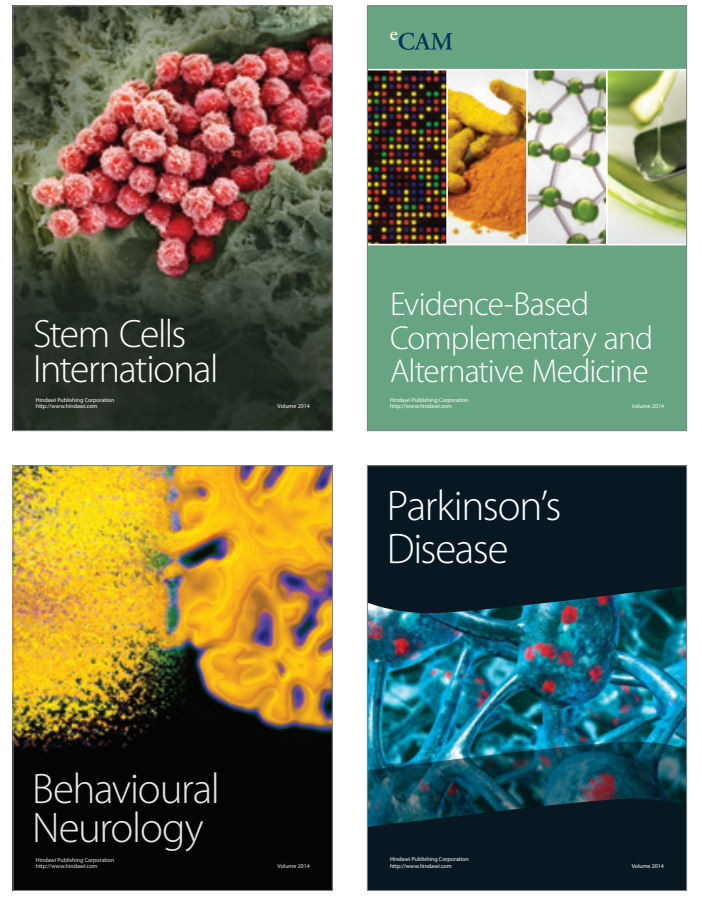
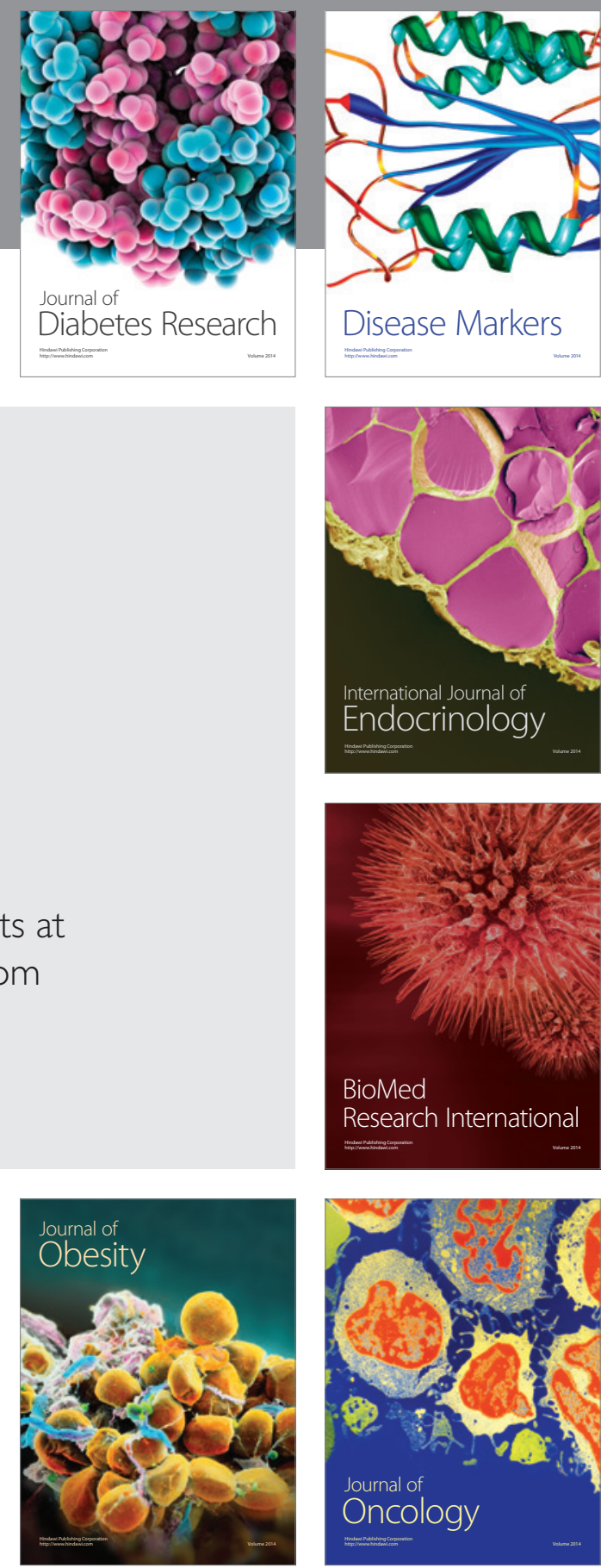

Disease Markers
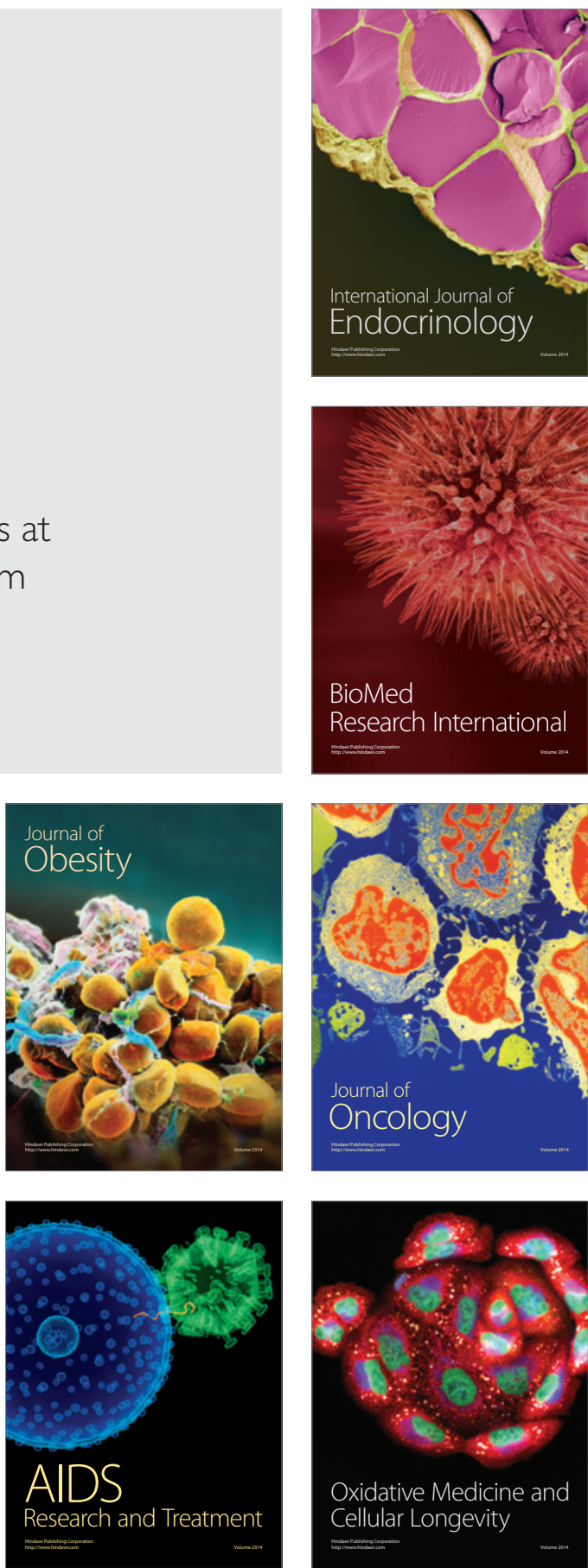